\title{
El panóptico de Bentham en los proyectos de la Academia (1814-1844)
}

\author{
José Enrique García Melero *
}

\begin{abstract}
RESUMEN
En este artículo se estudian los proyectos arquitectónicos sobre cárceles, conservados en la Real Academia de Bellas Artes de San Fernando en Madrid, que siguen el modelo de panóptico diseñado por el inglés Bentham. Fueron realizados por algunos de los pretendientes a los títulos de arquitectos y de maestros de obras. Formaban parte de las llamadas pruebas de pensado, que era el examen previo a la prueba de repente. Se proyectaron durante la primera mitad del siglo XIX. Constituyen un grupo destacado de un conjunto de proyectos, que siguen modelos distintos: tradicionales de planta rectangular a modo de palacios fortificados, novedosos como la cárcel de Gante y el penal de Filadelfia... El artículo se introduce con el estudio de los principales modelos internacionales de cárceles, realizados durante la época de la llustración, que eran conocidos en España.

\section{ABSTRACT}

In this paper the architectonic projects about prisons which have been preserved in the Royal Academy of Fine Arts of Madrid and which follow the panoptic model designed by Bentham are described. The se projects were realised by some of the applicants to the degrees of architects and master builders. The projects were part of the «pruebas de pensado" which was a previous exam to the «prueba de repente». These projects were realised in the first half of the XIX century. They are a remarkable group of projects in a set of projects that follow distinct models such as, traditional rectangular ground plants like the fortificated palaces, novel models like the prison of Gante and Philadelphia, etc.. The paper starts with the study of the main international prison models which were realised in the Enlightenment and which were known in Spain.
\end{abstract}

\footnotetext{
* Departamento de Historia del Arte. UNED.
} 
«En el panóptico, cada uno, según su puesto, está vigilado por todos los demás, o al menos por alguno de ellos; se está en presencia de un aparato de desconfianza total y circulante porque carece de un punto absoluto. La perfección de la vigilancia es una suma de insidias».

(Michel Foucault, «El ojo del poder»).

En 1790 se publicó en Londres el libro de Jeremías Bentham titulado el panóptico, donde el inglés estableció un nuevo modelo de cárcel, que tuvo una amplia repercusión sobre todo teórica, pero a veces también práctica, en Europa durante la primera mitad del siglo $\mathrm{XIX}^{1}$. Como es bien sabido se trataba de un proyecto en cierta forma «ideal», que intentó adecuar arquitectónicamente el encierro a la nueva normativa, en teoría más humanitaria, de la jurisprudencia de la llustración. Concedía al trabajo, la educación y la vigilancia para no delinquir de nuevo una prioridad total sobre el castigo. Pero el modelo de panóptico de Bentham era, además de destinarse a la cárcel, aplicable a otras muchas tipologías arquitectónicas, pues proporcionaba una serie de múltiples posibilidades diferentes, dada su condición moldeable: allí donde siempre fuera preciso establecer un sistema minucioso de control, como, por ejemplo, las fábricas y hasta, inclusive, los centros educativos.

El edificio propuesto por el inglés se apoyaba en una arquitectura pretensiosamente óptica, que hasta entonces había tenido en el teatro su principal manifestación, así como también en el mismo hospital. Establecía un nexo racionalista y metódico de dependencia funcional con la jurisprudencia a través de la conjunción entre esta Bella Arte, la más útil de todas socialmente considerada, y la física, a la vez que se concedía al dibujo un papel mucho más secundario como simple forma de expresión instrumental y no como un fin exclusivo en sí mismo. Había, pues, un paralelo con respecto a esos otros dos tipos de edificios en este mismo sentido, ya que, si el teatro se relacionaba como lugar del espectáculo con la literatura y la música, el hospital lo hacía con la medicina en calidad de sitio de curación de la enfermedad física. En medio entre la prisión y el hospital se hallaba el manicomio, que atendía a los males psíquicos y precisaba de una vigilancia atenta. La arquitectura trataba, así, de hacerse prácticamente funcional a la vez que científica, y el clasicismo se concebía ya como un sistema tan sólo de referencia, nunca básico en un sentido estricto.

BENTHAM, Jeremy, Panopticon; or, The inspection-house: containing the idea of a new principle of construction applicable to any sort of establishment... Dublin, Payne, 1791.- BENTHAM, J., «El panóptico». Edición facsímil de la castellana de 1822. Madrid, Editorial La Piqueta, 1979.- BENTHAM, J., Compendio de los tratados de legislación civil y penal. Madrid, Vda. Calleja e hijos, 1839. 
La cárcel fue una de las tipologías que más ocuparon a los principales arquitectos durante las décadas de transición entre los siglos XVIII y $\mathrm{XIX}$, pues se conservan proyectos importantes de Ledoux, Durand, Dance, Soane, Bentham... Pretendían definir a modo de ensayos realizables una serie de modelos de una tipo arquitectónico todavía entonces algo desdibujado por las escasas referencias de los tratadistas clásicos a ella. Vitruvio la había «olvidado», quizá con cierta alevosía, al no concederla ninguna importancia y definir tan sólo su ubicación en el foro de la ciudad, y Alberti, consciente de la falta, trató de establecer un sistema formal, que resultó ser todavía un tanto diluido; pero que sí fue un importante punto de partida y una referencia ineludible. Los lugares de encuentro del hombre con su propia miseria existencial nunca debieron ser gratos, sino arquitectónicamente malditos, para el clasicismo. Parecía ocultar, deseando su abandono en un letargo mental, aspectos fundamentales en la vida del hombre, pero vergonzosos por recordar las limitaciones humanas, tales como, por ejemplo, la enfermedad, la pobreza, el crimen y el delito, y hasta la misma muerte, el mayor de los olvidos posibles.

\section{MODELOS TRADICIONALES Y NOVEDOSOS A PRINCIPIOS $D E L S I G L O X I X$}

El panóptico de Bentham también tuvo una importante repercusión en España y, en concreto, en la misma Academia madrileña, como centro rector entonces del arte con su doble objetivo a la vez conceptual y docente. Algunos de los pretendientes a los distintos títulos de la arquitectura -académicos de mérito, arquitectos o maestros arquitectos y maestros de obras- diseñaron en sus proyectos de exámenes para conseguirlos, las llamadas pruebas de invención o de pensado previas a la de repente, modelos que se adecuan al propuesto por el jurista inglés; pero estableciendo algunas variaciones notables. En el fondo Bentham tan sólo proporcionó, lo que no es poco sino demasiado, unas directrices generales, algo más que filosóficas y en calidad de primeros principios, como esquema esencial útil para la arquitectura, que los profesionales debían adecuar a la realidad y a las especificidades de las necesidades concretas.

En las décadas de transición entre los siglos XVIII y XIX se establecieron una serie de modelos de cárceles y submodelos, constituyendo auténticas familias, que de alguna forma estuvieron siempre presentes en los discípulos de la Academia a la hora de diseñar sus proyectos. Unos procedían de una tradición algo confusa aún, sin codificar totalmente; pero otros resultaban 
bastante más novedosos, o así se pensaba entonces ${ }^{2}$. Si éstos racionalizaron metódicamente el interior de la cárcel según las ideas de la llustración , aquellos la proporcionaron su «faz terrible», tan expresiva y tan romántica.

\subsection{Modelos tradicionales reformados: En busca de la elocuencia y la funcionalidad}

El pasado tenía, como principal referencia en España, la famosa cárcel de Corte de Juan Gómez de Mora, y a ella citaron de alguna forma muchos de estos proyectistas aspirantes a los grados de la Academia. Tal modelo parecía aludir a las cárceles como palacios fortificados a modo de cuarteles. Se constituyó en una línea que tal vez se pueda considerar como tradicional, pues su propuesta partía de Alberti. La planta era o rectangular o cuadrada, cuyas dependencias distintas se distribuian en torno a uno $o$ a varios patios. La fachada principal estaba flanqueada por dos torres en las esquinas, rematadas por chapiteles, y citaba, como referencia castiza de clasicismo, a El Escorial y a Juan de Herrera.

El palacio, derivado por evolución o variante de la cabaña primitiva o vivienda ahora ennoblecida, aparece, así, como un edificio que es mucho más que un "simple» tipo arquitectónico: un prototipo, un auténtico sistema modular acomodable según las exigencias de cada nueva época, como el mismo templo, a otras funciones distintas. Es un primer tipo, o prototipo, del que resultan después otras tipologías distintas, que ineludiblemente le citan siempre; pero de muy diversos modos: bien en su planta bien en la representación figurativa de su fachada, aún con variaciones más o menos notables.

Tal modelo tradicional de cárcel de planta palaciega rectangular o cuadrada, cuya referencia clásica es la propuesta por Alberti ${ }^{3}$, quiso ser modificado y actualizado por varios arquitectos de esta época de entre siglos. Éstos son los casos, como ejemplos bien representativos, de Ledoux y de Durand ${ }^{4}$. Si el primero deseó dar elocuencia total a sus diseños,

El presente estudio sirve de complemento y es continuación en el tiempo histórico de otro artículo, que publiqué en 1995 en esta revista, motivo por el cual no trato aquí sobre los modelos de Vitruvio, Alberti, la imagen de Piranesi..., ni acerca de la censura de las cárceles españolas en la Comisión de arquitectura de la Academia madrileña: GARcí MELERo, José Enrique, "Las cárceles españolas de la llustración y su censura en la Academia (1777-1808)". En Espacio, fiempo y forma, serie V!II, Historia del Arte, tomo 8. Madrid, Facultad de Geografía e Historia de la UNED, 1995, págs. 241-272, con láms.

3 AlberTI, León Batista: Los diez Libros de Architectura de... Traducidos de Latín en Romance. Madrid, Alonso Gómez, año de 1582. BRASF: B-1810.

4 Libro importante es: ViDLER, Anthony, El espacio de la llustración. Madrid, Alianza Forma, 1997. 
sobre todo de fachada, para unas prisiones en Aix-en-Provence entre 1783 y 1785, el segundo pretendería ser más funcional en su modelo, aún partiendo de él; pero basado en un sistema reticular. Ledoux aspiraba a hacer hablar a sus edificios, de tal manera que su forma siempre expresase visualmente a la perfección su función a simple vista, sin que la mirada racional tuviera apenas que trabajar. Sin embargo, lo hizo sin ninguna exagerada retórica formal, pues trató de hallar la máxima simplicidad expresiva. De aquí que su principal aportación se halle más en la figurativa representación de la fachada que en la misma planta de su cárcel, que sigue la línea tradicional clásica.

Ledoux partió del hospital renacentista en sus diseños de planta para la prisión de Aix-en-Provence. Bentham también lo haría muy pocos años después; pero aludió a los modelos hospitalarios más de su época, como el de Petit, que a los paradigmas del Renacimiento. Así, el francés dispuso una tradicional cruz griega inscrita en un cuadrado, que formaba cuatro patios con respecto a las otras tantas crujías de las fachadas. En el lugar clave de encuentro entre sus brazos situó, como en esa otra tipología hospitalaria, la capilla. El sistema de planta de cuatro crujías y los otros tantos pisos del edificio proporcionaba un sistema arquitectónico de fácil clasificación de los presos en espacios distintos según las diversas categorías establecidas por la jurisprudencia, que, además del sexo y de la edad, consideraba también básico la gravedad del tipo de delito cometido (lám. 1).

Sin embargo, tal y como ya se ha indicado antes, la principal aportación del modelo concreto de Ledoux es la faz concreta e identificable dada al edificio, que resulta tan terriblemente elocuente. La fachada caracterizaba teatralmente la función de su prisión, como las máscaras a los actores durante la representaciones teatrales de la Antigüedad (lám. 2). Su gravedad escueta, la casi ausencia de huecos y su pequeñez, su robustez, sus gruesos muros, faltos de todo almohadillado y de motivos decorativos... expresan su finalidad tan peculiar: privar al hombre de toda libertad exterior y encerrarle en sí mismo siempre entre sus iguales. Se creaba, así, un mundo interior tan singular, una especie de escueta ciudad aislada y fuera de toda realidad exterior a ella. Apenas hay sitio para el empleo de los órdenes arquitectónicos a no ser en su pórtico de entrada con sus columnas dóricas sin basa y sus frontones curvos, que forman un cuarto de cilindro.

Se podría cuestionar aquí la aportación novedosa de Ledoux al proporcionar el rostro más aparente de la cárcel, si consideramos también la prisión de Newgate que George Dance el Joven inició ya en 1770 y que 


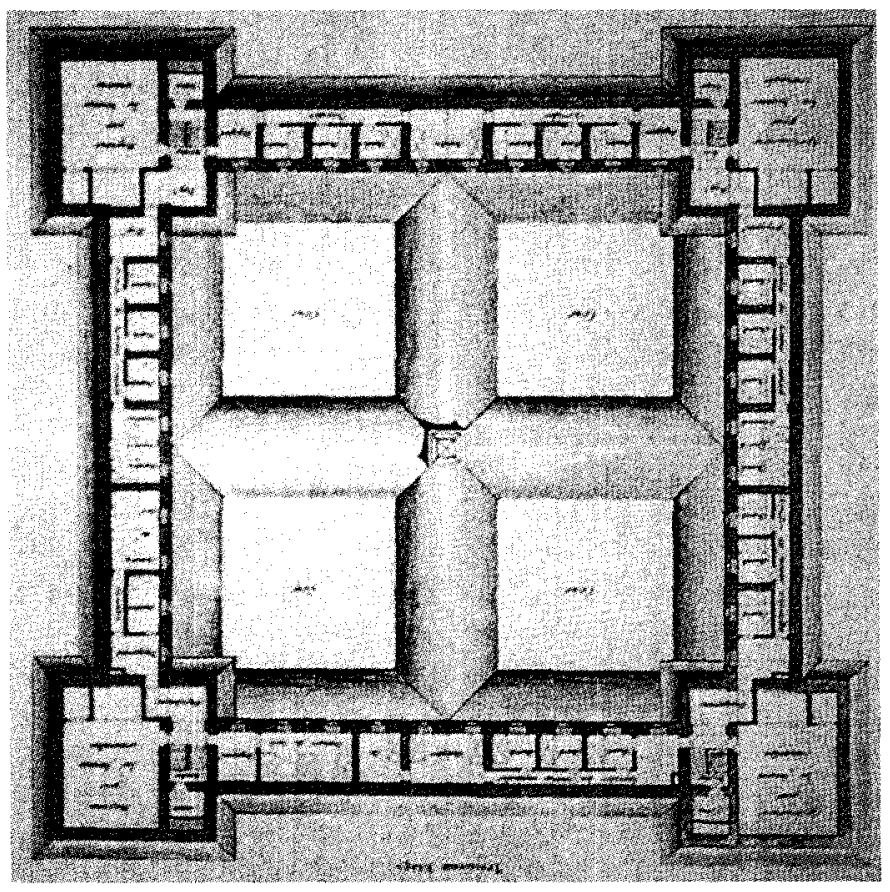

Lám. 1. Ledoux: Planta de la prisión de Aix-en-Provence. 1783-1785. Parte del modelo hospitalario renacentista de planta de cruz griega inscrita en un cuadrado.

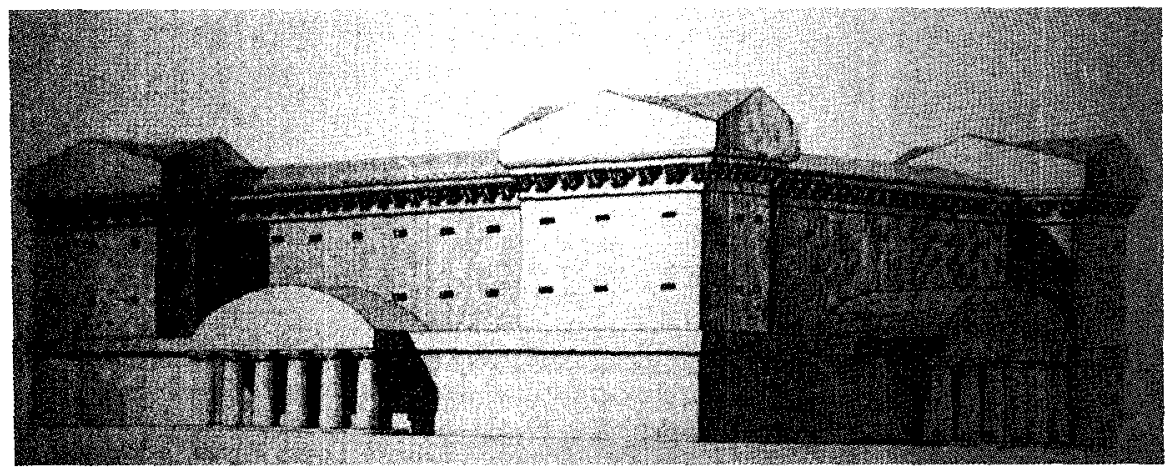

Lám. 2. Ledoux: Fachada del proyecto para la prisión de Aix-en-Provence. 1783-1785. La fachada caracteriza teatralmente la función de la prisión, como las máscaras a los actores durante las representaciones teatrales de la Antigüedad. 
Durand incluyó como un modelo inglés en su Recueil et paralléle des edificies. Tal obra, demolida en 1903, plantea esta tipología como si fuera una auténtica fortaleza, donde se cita a Palladio y a Giulio Romano. La planta queda constituida por el encuentro entre tres rectángulos, cuyas crujías encierran otros tantos patios. La unión de estas figuras se realiza irregularmente por medio de unos cuerpos en avance y otros en retroceso para proporcionan luces y sombras a las fachadas al modo de Boullé $e^{5}$. Éstas se almohadillaron totalmente. Sólo había cinco filas de huecos en la parte central de la principal, que se correspondía con la residencia del gobernador, flanqueada por dos bloques autónomos a modo de portaladas. Además, estableció falsas ventanas a intervalos regulares y colocó simbólicamente cadenas colgantes en las puertas Así, logró una gran elocuencia simbólica, como un precedente ineludible del modelo de Ledoux, que Howard reprodujo en su extraño y filantrópico viaje tan ilustrado por las prisiones de Europa.

Otra opción de cárcel, que se basa en calidad de un submodelo en gran medida en el de Ledoux, es la proporcionada por Durand en su proyecto de 1791, realizado en colaboración con Thibauld para sus alumnos de la Ėcole Polythecnique ${ }^{6}$. Sin embargo, contradiciendo en algo a aquél, procuró que el exterior del edificio no resultara tan terrible, sino que sólo insinuase su función con cierta sencillez. Como la prisión de Ledoux, la planta propuesta por Durand es cuadrada; pero con cuatro cuerpos también de esta misma figura a modo de torres en los ángulos muy sobresalientes a las líneas del exterior, que interiormente se corresponden con los servicios generales de la prisión: cocinas, refectorios, enfermerías, cuerpos de guardia... No obstante, en base a la aplicación de un sistema reticular, trazó dos crujías paralelas a sendas fachadas laterales. El espacio quedó dividido en siete partes de dos pisos de altura general, que en las torres era de tres. Se definieron, de esta forma, en su interior otros tantos patios alargados paralelos entre sí y perpendiculares a las fachadas principal y posterior (lám. 3). El central servía de desahogo del edificio y los laterales se destinaban a cada sexo: el de la derecha a los hombres y el de la izquierda a las mujeres. Se seguía, así, la clásica distribución de los hospitales ${ }^{7}$.

5 Chueca Goltia, Fernando, Neoclasicismo. Madrid, Dossat, 1985. (Historia de la Arquitectura Occidental, IX), pág. 154.

6 DuRAND, J.-N.-L, Nouveau précis des leçons d'architecture données à l'École Impériale polytechnique. París, 1813.

7 Sobre Durand: SzamBien, Werner, Jean-Nicolas-Louis Durand. 1760-1834. De l'imitation à la norme. París, Picard, 1984. 


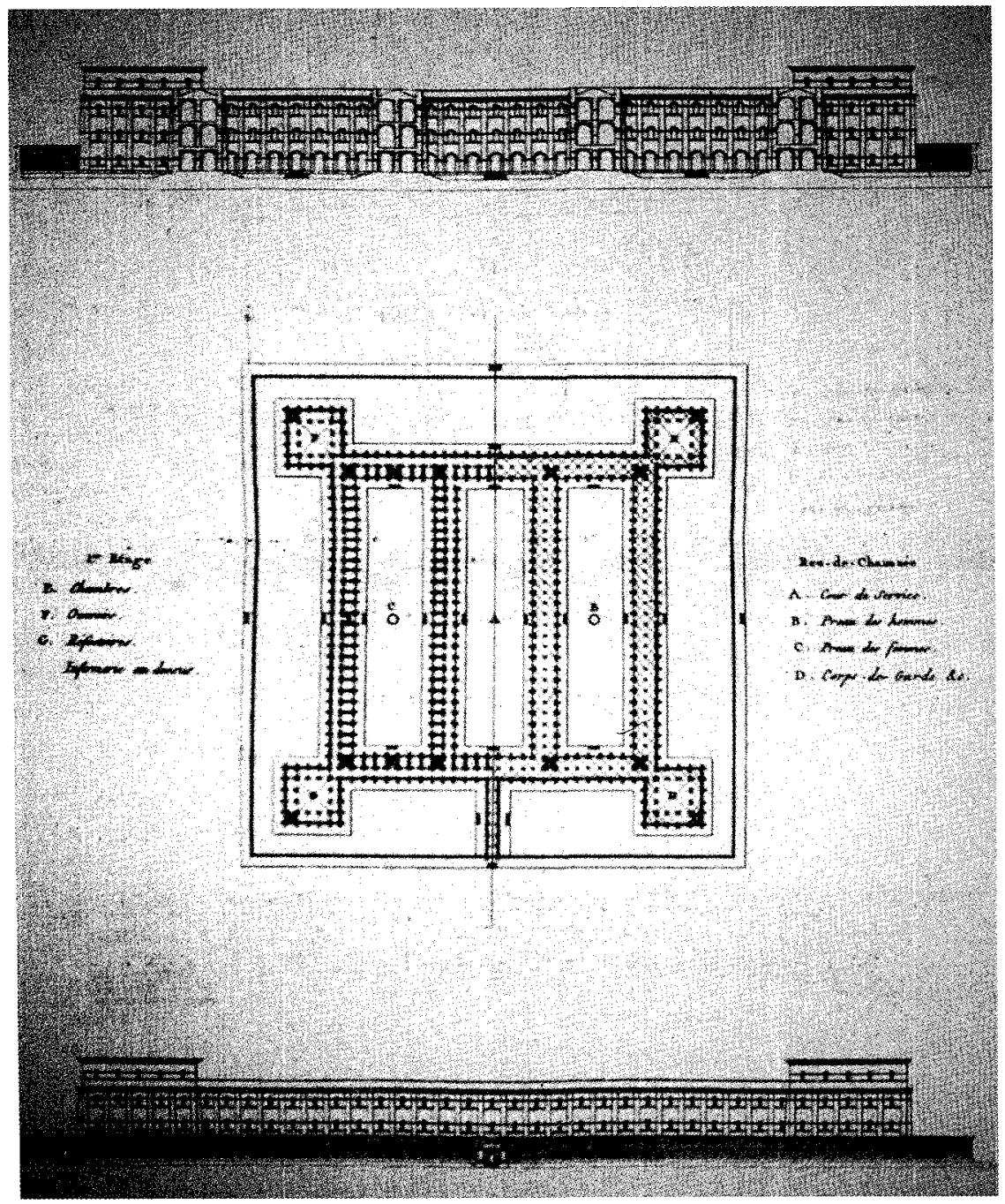

Lám. 3. Durand, proyecto de cárcel de 1791, realizado en colaboración con Thibauld para sus alumnos de la Ėcole Polythecnique. 


\subsection{Los nuevos modelos: Del sistema radial de la prisión de Gante al panóptico de Bentham}

Frente a la prisión tradicional de planta rectangular o cuadrada a modo de un palacio fortificado, que fue objeto, tal y como ya se ha visto antes, de remodelaciones en busca de submodelos, se crearon nuevos ejemplos durante el último cuarto del siglo XVIII y principios del XIX. Ello supuso una auténtica renovación basada en la ciencia y más concretamente a la vez en la física y en la jurisprudencia, y de una manera indirecta hasta en la misma medicina, tal y como se indicará a continuación. Los tres logros más destacados fueron las plantas proporcionadas por el correccional de Gante, por el panóptico de Bentham y por la cárcel de Filadelfia. Se pasaba, así, de unas plantas rectángulares o cuadradas a modo de palacios fortificados a otras de carácter central, circular, dodecagonal, octogonal y hexagonal con radios o sin ellos. Los cambios en el diseño de las cárceles estaban ya entablados a finales de la centuria de la llustración con toda la claridad posible.

1.2.1. Los nuevos modelos de cárcel y su relación con los proyectos de hospitales de Petit y Poyet

La reciente renovación arquitectónica del hospital en Francia influyó entonces más que nunca en el diseño de la cárcel al establecerse un cierto paralelismo entre ambas tipologías. Ello se debió a varios motivos, de entre los que destacarán aquí dos en concreto: en primer lugar a causa de la necesidad existente en una y otra de seguir un sistema de clasificación de sus habitantes para impedir, en la una, el contagio de las enfermedades infecciosas y de los males morales, en la otra. Además, porque era ya imprescindible conseguir la higiene necesaria y la ventilación imprescindible en ambos establecimientos, donde tenían que coexistir un gran número de personas más o menos apiñadas y en espacios mayores o menores.

Los nuevos modelos franceses de hospitales, que influyeron sin ninguna duda en las prisiones, se diseñaron con motivo del incendio del Hôtel-Dieu en 1772, suceso tan similar a la anterior destrucción por el fuego del Teatro de la Ópera de París algunos pocos años antes, en concreto, en 1763. Hubo durante las décadas siguientes importantes debates para reedificarle, tal y como ocurrió con este edificio para el espectáculo musical, y se diseñaron entonces una serie de opciones posibles ${ }^{8}$.

3 García MELero, José Enrique, «Los modelos de la tipología del teatro a finales de la Ilustración en España». En «Espacio, tiempo y forma», serie VII, núm. 7. Madrid, U.N.E.D, 1994, 
Así, por ejemplo, Antoine Petit, médico y profesor de anatomía y cirugía de la Universidad de París, proyectó un nuevo hospital de forma circular para reconstruirlo, ideado tan sólo dos años después de tal suceso ${ }^{9}$. Por consiguiente, la renovación de dos tipologías tan significativas en la Francia de la llustración fueron motivadas por otros tantos acontecimientos similares tan desgraciados y por los consecutivos sendos procesos discursivos. En tales debates también se establecieron una serie de paralelos comparativos entre los distintos modelos existentes, respectivamente, de teatros y de hospitales. Ello propició de algún modo el historicismo decimonónico.

Petit dispuso en su proyecto circular radial seis crujías, que parten del centro del círculo a intervalos regulares (lám. 4). Se constituyen de esta forma otros tantos pabellones aislados para pacientes de diversas enfermedades, en concurrencia con respecto a una capilla también circular. Los oficios religiosos serían visibles para los enfermos desde todas estas salas radiales, tal y como se había programado en el modelo de planta de cruz griega renacentista. Pero tal sitio clave, cubierto con una bóveda a modo de embudo invertido con la finalidad de facilitar la circulación del aire, era, asimismo, el lugar de ubicación de las enfermeras, desde el cual siempre veían y hasta oían todo lo que acaecía en las distintas salas. En la crujía circular externa se situaban los servicios generales: cocinas, panaderías, botica, las habitaciones del cirujano... Entre las crujías se abrían patios de forma triangular con uno de sus lados curvos también clasificados por enfermedades con galerías cubiertas con arcadas. De esta forma el aire circulaba entre ellas, ventilando el interior según las normas de la higiene.

Bentham en su panóptico ya posterior en dieciséis años, de 1790, parece tomar, como después se verá, muchos elementos de este modelo de hospital de Petit. Así ocurre principalmente con su planta general circular; pero, sobre todo, con el centro mismo de este círculo, donde el inglés colocó la torre de vigilancia. Desde ella el guardián observaba atentamente todo lo que ocurría en el interior de las celdas dispuestas en su perímetro. El lugar de ésta estaba ocupado en el hospital proyectado por el francés por la capilla y por las enfermeras. Por ello el jurista la concedió la doble

págs. 213-246. (La tipología del teatro y la Academia). GARCía MELERO, José Enrique, «Historicismo y eclecticismo en el debate internacional sobre la curva del auditorio teatral durante la llustración» Goya, núm. 246, págs. 338-348, con 15 láms. Madrid, Fundación Lázaro Galdiano, 1995. García Melero, José Enrique: Génesis y conceptos urbanístico y arquitectónica del primitivo Teatro Real de Madrid. En “Reales Sitios», año xxxv, xxxıv, núm 132. Madrid, Patrimonio Nacional, $2 .^{\circ}$ trimestre de 1997, págs. 53-67, con 10 láms.

9 PETIT, Antoine, Mémoire sur la meilleure manière de construire un hôpital de malades. París, 1774. 


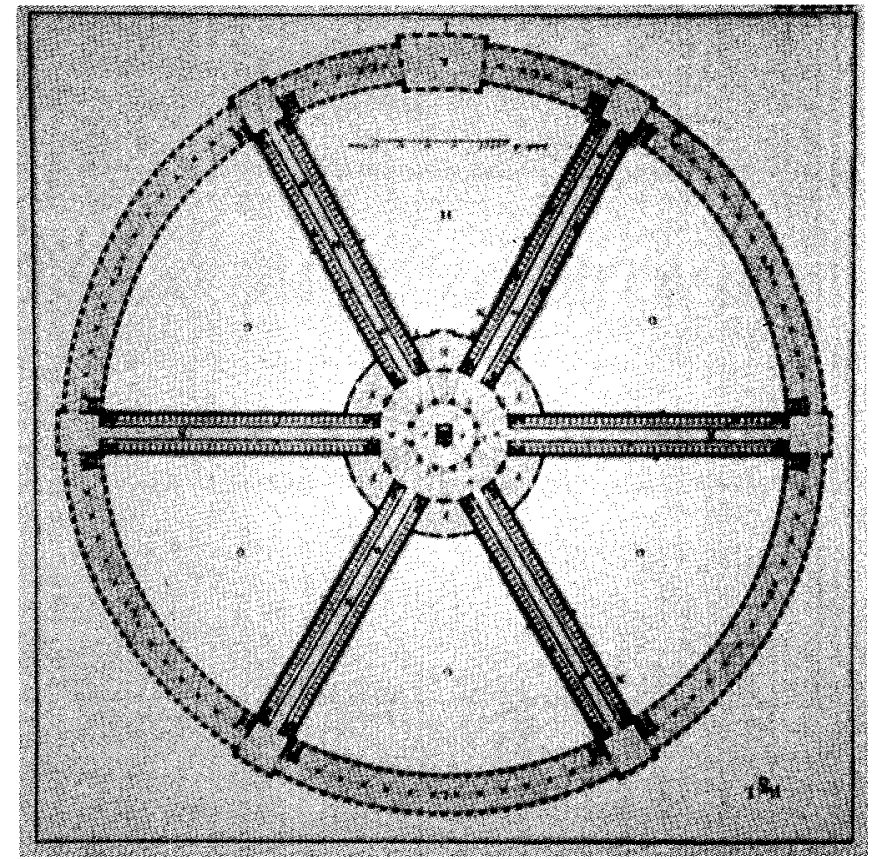

Lám. 4. Proyecto de Antonine Petit para Hôtel-Dieu de 1774. Era médico y profesor de anatomía y cirugía de la Universidad de París.

función de sitio de vigilancia y, asimismo, de lugar de celebración de los oficios religiosos, tal y como Petit hizo en su diseño ${ }^{10}$.

Sin embargo, el proyecto del arquitecto Bernard Poyet, ya de 1785, quien de la misma forma partió de Petit, parece acercarse aún más a la concepción de Bentham, cuyo diseño es tan sólo cinco años posterior. Su hospital era también circular con pabellones radiales ${ }^{11}$. Estas crujias quedaban doblemente unidas: con el círculo exterior y con otro concéntrico. En el plano, donde ubicó su Hôtel-Dieu en París a orillas del Sena, adquiere el aspecto de un auténtico ojo humano al ser contemplado por el espectador. Su hospital tiene auténtica forma de pupila humna. Parece, así, aludir a la estrecha relación que esta tipología también posee con la

10 VIDLER quiere ver en la ciudad de los vientos vitruviana el precedente de esta idea de Petit. Op. cit., El espacio de la llustración. Madrid, Alianza Forma, 1997, págs. 94 y 95.

11 POYET, Bernard, y COQUÉAu, Claude-Philibert, Mémoire sur la nécessité de transférer et reconstuire l'Hôtel Dieu de Paris suivi d'un projet de trnslation de cet Hôpital, proposé par el Monsieur Poyet, arch., et contrôleur des bâtiments de la ville. París, 1785. 
óptica. Recuérdese aquí que Ledoux antes había representado vanidosamente, asimismo y de forma mucho más figurativa, su sala de teatro de Besançon, construida entre 1779 y 1784 y aludiendo al teatro Olímpico de Palladio, tal y como si se reflejara en la pupila de su propio ojo. Uno y otro eran, así pues, conscientes de la existencia de una arquitectura propiamente óptica, que relacionaba el teatro con el hospital.

\subsubsection{La planta radial del correccional de Ackerghem en las afueras del Gante}

Un modelo concreto de cárcel de planta radial, reproducido por Howard, que repercutió en algunos proyectos presentados en la Real Academia de San Fernando, fue la Maison de Force, realizada para correccional de Flandes. Construida por iniciativa del vizconde Vilain entre 1772 y 1775 según proyecto de Malfaison y Kluchman, se halla en Ackerghem, en las afueras de Gante ${ }^{12}$.

Howard consideró a este correccional como una gran innovación en su

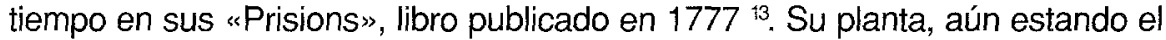
edificio todavía entonces incompleto cuando el inglés le vio, era, tal y como demuestra el dibujo incorporado, un hexágono regular, de cuyos vértices partían cuatro radios; pero su plan definitivo resultó un octógono también regular de ocho radios. La disposición de estas crujías de cuatro pisos cada una de ellas permitía el sistema de clasificación de los presos por pabellones aislados y celdas individuales. Entre eilos se formaban otros tantos patios trapecioidales útiles para seguir a la hora del recreo este mismo sistema de separación por sexos, edades y tipos de delitos cometidos. En el centro se inscribía otro octógono de servicios también con su correspondiente patio interior de desahogo general, con el que se comunicaban los demás. El sistema parece inspirarse con gran fidelidad en el proyecto de hospital de Petit de 1774.

El sistema de prisión radial tuvo un gran éxito tanto durante las décadas finales del siglo XVIII como a lo largo de la primera mitad del XIX. Fue empleado por William Blanckburn en varias ocasiones, como es el caso de la cárcel de Ipswich (1785-1790), donde las cuatro crujías, que parten de un cuerpo central octogonal regular, forman una aspa al encontrarse con uno de los lados en alternativa de la figura octogonal exterior.

\footnotetext{
12 Pevsner, N., Historia de las tipologias arquitectónicas. Barcelona, Gustavo Gili, 1979, Pág. 193, Tít. original: A History of Building Types. Nueva Jersey, Princenton, 1976.

13 HowARD, John, The State of the prision in England and Wales (1774-1784)... London, 1787. Etat des prisions, des hopitaux et des maisons de force. Paris, Lagrange, 1788.
} 


\subsubsection{El panóptico de Bentham}

El libro de Jeremy Bentham (1748-1834), un auténtico filósofo de la jurisprudencia, publicado en $1791^{14} \mathrm{iba}$ a revolucionar la tipología carcelera decimonónica. Se basaba en los conceptos de utilitarismo, de hedonismo social y de la aritmética moral, y hacía coincidir éticamente el bien con el placer y el mal con el dolor. Estableció una escala comparativa de los distintos placeres en función de su relación con la felicidad. Bentham basaba su diseño de cárcel en su peculiar visión filosófica del derecho, con la cual era totalmente congruente. Su modelo tuvo una acogida rápida en Europa. Las líneas maestras del proyecto del inglés repercutieron en los diseños decimonónicos de las prisiones europeas, en especial entre 1830 y 1840 , con ligeras modificaciones en busca siempre de lograr una mayor funcionalidad. De esta forma las veremos representadas con ciertas alteraciones personales en los dibujos de los pretendientes españoles a los títulos de arquitectos y de maestros de obras concedidos por la Academia madrileña.

Proponía, como casa de reclusión en forma de colmena y a modo de una urbe represiva y aislada en sí misma dentro de la ciudad, una planta circular de alzado cilíndrico con foso exterior y de seis altos. Las celdas individuales se disponían a lo largo de la circunferencia. Estarían abiertas por la parte interior y protegidas por una reja de hierro. Se multiplican las ventanas hacia el exterior en el panóptico, como alivio visual de la cautividad y en calidad de medio de salubridad. Además, proporcionaban la suficiente luz al interior para propiciar la vigilancia, pues las siluetas de los prisioneros quedaban recortadas por los rayos luminosos. Así, el inspector podría saber lo que cada uno de ellos estaba haciendo en todo momento. La celdas se comunicaban por medio de una galería de circunvalación, a la que sus puertas se abrían. En el centro ubicó una especie de puente, o torre de vigilancia, cubierta en lo alto por una vidriera y dividida en tres pisos. Cada uno de ellos se dispuso de tal forma que el vigilante invisible dominaría visualmente dos líneas de celdillas. La torre, asimismo, quedaba rodeada por medio de una galería cubierta con una celosía transparente, desde la cual era posible contemplar todo lo que ocurría en las celdas, sin que el guardia pudiera ser visto desde el exterior. Se jugaba, así, no sólo con la certeza de la visión misma, con el poder de la mirada fija,

\footnotetext{
14 Bentham, Jeremy: Panopticon; or, The inspection-house: containing the idea of a new principle of construction applicable to any sort of establishment... Dublin, Payne, 1791. BentHAM, J.: El panóptico. Edición facsímil de la castellana de 1822. Madrid, Editorial La Piqueta, 1979.- BENTHAM, J.: Compendio de los tratados de legislación civil y penal. Madrid, Vda. de Calleja e hijos, 1839.
} 
sino también con la idea, muchas veces ilusoria, de una presencia continua y omnipresente, aunque el inspector se ausentase de la torre. Pero, además, no sólo vigilaba a los presos sino a los mismos vigilantes, que siempre debían hallarse en su sitio de guardia (lám. 5).

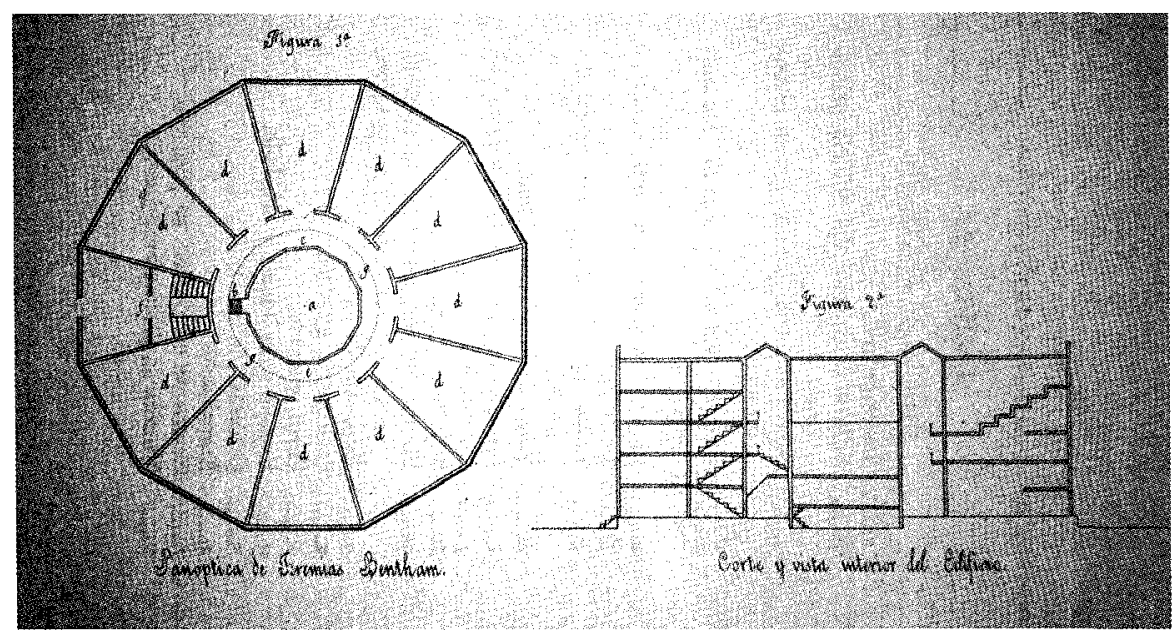

Lám. 5. Bentham: Panóptico. 1790. Madrid, 1822. Leyendas: a) Torre o inspección central. b) Principio de la escalera a la torre. c) Espacio anular entre la torre y el edificio principal. d) Celdas. e) Escalera principal. f) Entrada. g) Galeria.

En realidad, el proyecto de Bentham incluye, por consiguiente, dos edificios diferentes concéntricos y enfrentados entre sí, pues quedan perfectamente encajados el uno, la torre, dentro del otro, la parte dedicada a los prisioneros. Sin embargo, entre ambos se deja un espacio anular vacío, o pozo circular, para impedir que los presos intentaran cualquier tipo de motín contra los inspectores. Por medio suyo el sitio del poder en lo alto y en el centro quedaba perfectamente diferenciado del lugar de la represión.

Así, se jerarquizan y aíslan los dos espacios principales del edificio entre sí: desde el central se vigila atentamente a los condenados, siendo, por tanto, el lugar del poder silencioso, que se siente sin percibirse visualmente y que impide hacer nuevo mal. En el entorno exterior se sufre ante la idea de la vigilancia continua. Es el sitio de la sumisión forzada y de la obediencia maquinal. Entre ambos se halla ese foso inaccesible a modo de vacío, que distancia el poder del colectivo de reos, dispuestos individualmente en sus celdas para incomunicarlos y aislarlos entre sí. Este lugar de vigilancia cambiaba su aspecto los días festivos, al abrirse las 
celosías de las galerías y aparecer un altar. De esta manera los presos podían contemplar y oír desde sus celdas los santos oficios. Mirando hacía la torre, la única perspectiva visual posible, donde ese altar sustituía a los inspectores durante los días festivos, debían orar. De esta forma el espacio concreto para el poder temporal, siempre distante de algunos hombres, se sacralizaba de algún modo, al identificarse con el mismo sitio simbólico de un Dios sin tiempo. Se creaba, así, una relación paralela entre el gobierno divino y justiciero, y el humano de unos pocos, incapaces de perdonar sin castigo la infracción de sus propias normas. También se enfrentaban dos espacios circulares concéntricos entre sí en calidad de doble bóveda celeste. Además, el panóptico, donde todo se ve, queda protegido del exterior por medio de una especie de fortificación rodeada por un muro cuadrangular con empalizada, que singularizaba su espacio global, un microcosmos represivo.

El ilustrado Bentham, a pesar de esta estrecha vigilancia omnipresente, que resulta un auténtico castigo para el reo, trató de humanizar la casa de reclusión de alguna manera a base del empleo de la técnica, especialmente física, no psíquica; mas buscando siempre un sentido económica y socialmente utilitario. Lo hizo abriendo muchos vanos, que iluminan y ventilan todo el interior; pero que también permite ver mejor las siluetas y los movimientos de los prisioneros a los inspectores desde la torre. Asimismo, dispuso una especie de sistema de calefacción para las celdas por medio de una serie de tubos conductores del calor, que, también sirven para renovar el aire del interior y hasta para que el preso pueda oír la voz del inspector. Por medio de otros se introduce, se conduce y se distribuye el agua por las celdillas desde un depósito situado alrededor de lo alto del edificio. Sin embargo, el humanismo del inglés, como hombre de la llustración, es utilitario -las utopías siempre se proyectaban para realizarse-, pues piensa que por medio del cuidado de todos estos aspectos arquitectónicos, que permiten más seguridad y también higiene, se facilita y se puede aumentar el trabajo productivo del reo sin interrupciones. De aquí el papel fundamental desempañado por los talleres en estas cárceles.

Su propuesta, basada en el estudio de la experiencia arquitectónica de los hospitales, tenía un indudable componente ético, pues trataba de asegurar la buena conducta de los presos con respecto a unas normas más o menos convencionales y convincentes de la sociedad, así como alcanzar su enmienda, por mediación de este sistema de vigilancia visual continua. Además, proponía la idea de aislamiento y de control constante de los reclusos. Era optimista con las posibilidades de la arquitectura, que de esta forma se convierte en una auténtica máquina, si se empleaba de una forma adecuada a su función. En esta tipología consistía en aumentar la 
seguridad de las cárceles, disminuir el gasto y mejorar la salubridad, la limpieza y el orden. No obstante, era preciso que la casa de reclusión se gobernase por medio de determinados principios, como los de dulzura y economía; pero, sobre todo, por la norma de la severidad: la mirada severa y atenta sin ningún parpadeo.

El sistema de Bentham fue ampliamente divulgado en España a través del libro de J. Villanova y Jordán titulado Aplicación de la panóptica de Jeremías Bentham a las cárceles y casa de corrección de España, que salió a la luz en $1834{ }^{15}$. En su opinión el panóptico era una especie de «teatro moral». Además, modificó el sistema panóptico para hacerlo más operativo, ampliando el patio central, quitándole la cubierta, estableciendo celdas individuales y colectivas...

\subsubsection{La cárcel del Este en Filadelfia}

Uno de los pretendientes al título de maestro de obras de la Academia madrileña, José M. ${ }^{2}$ de Mariategui ${ }^{16}$, indicó inadecuadamente que su proyecto de 1830 seguía el sistema empleado en la cárcel del Estado Penitenciario del Este de John Haviland en Cherry Hill, cerca de Filadelfia, en Pennsylvania, que se construyó entre los años 1823 y 1835, según diseño de $1825^{17}$. El proyecto de este edificio está basado en una concepción funcional del presidio, aunque su imagen fuera la de un castillo, careciendo de motivos griegos y aludiendo al gótico, estilo tan del gusto entonces. La idea era aislar totalmente al preso tanto de día, trabajando en su celda, como de noche.

Su planta general, que sigue de alguna forma el modelo del correccional de Gante, es un cuadrado en el que se inscriben siete crujías radiales a intervalos regulares en forma de aspa, donde se disponen las celdas. Constituyen pabellones aislados útiles para el sistema de clasificación de los presos en función de distintos conceptos. Entre dichas aspas se definen seis patios triangulares propios para cada pabellón, a los que hay que añadir un séptimo de desahogo, que comunica con la entrada y los servicios generales del presidio. John Haviland tomó de Bentham la idea de un

\footnotetext{
15 Villanova y Jordán, J, Aplicación de la panóptica de Jeremías Bentham a las cárceles y casas de corrección de España... Madrid, Imprenta de Tomás Jordán, 1834.

16 MARIATEGUI, José María de, Informe facultativo sobre la composición de un proyecto condestino a Cárcel Correccional. 1830. AASF: 9-4/2.

17 Hітснсоск, Henry-Russell, Arquitectura de los siglos XIX y XX. Madrid, Cátedra, 1981, pág. 131 y 132.
} 
pabellón central de vigilancia absoluta, a donde confluían tales crujías radiales, influidas por la Maison de Force de Gante y la prisión posterior en el tiempo derivado de él de Ipswich de William Blanckburn; realizada entre 1785 y 1790 . Estableció, así, una síntesis entre dos modelos preferentes de referencia entonces ineludible: el radial y el panóptico.

\section{PROYECTOS DE CÁRCELES EN LA ACADEMIA}

En la Real Academia de Bellas Artes de San Fernando se localizan muchos y muy variados proyectos de cárceles, diseñados, sobre todo, durante la primera mitad del siglo XIX, aunque también los hay de la época ilustrada. La mayoría de ellos son dibujos hechos para pasar la llamada prueba de pensado o de invención, aunque se consevan algunos pocos diseñados para la de repente, necesaria como condición previa para examinarse a fin de obtener los títulos de arquitecto y de maestro de obras. También existen algunos pocos discursos a nivel teórico sobre este edificio redactados por aspirantes al grado de incorporación de académicos de mérito ${ }^{18}$.

Tales proyectos, conservados hoy en el Gabinete de Estampas y Dibujos de la Academia, se relacionan estrictamente con determinados legajos existentes en el Archivo de este centro ${ }^{19}$. En ellos se encuentran documentación sobre su formación profesional así como los informes facultativos de los diseños escritos por los aspirantes. A la valiosa información biográfica suministrada - como partidas de bautizo, certificados de buena conducta y de asistencia práctica a los estudios de arquitectos, asignaturas cursadas, actividad profesional previa...- hay que añadir esos imprescindibles informes facultativos, donde se justifican de forma más o menos pormenorizada según cada individuo el proyecto global y los dibujos diseñados sobre cada uno de sus aspectos, el modo de construirle, los materiales empleados y el coste económico de las obras. Así, diseños

18 BARra, Francisco, Determinar qué circunstancias y clases de distribución deben darse a la cárcel pública capaz de contener de 300 a 400 presos; y cómo se hará compatible la seguridad de éstos con la luz y ventilación de las piezas aún para mayores reos. Madrid, 1832. AASF.: Leg. 313-2/3. (Disertación para el grado de incorporación de académico). No tiene diseños. CABRERA PÉREZ, Manuel, Demostrar qué circunstancias y clase de distribución deben darse a una cárcel pública... Madrid, 1942. AASF: 308-44/3.

19 Quiero agradecer aquí las facilidades halladas en el Gabinete de Estampas de la Academia a Silvia Arbaiza e Isabel Azcárate Luxán. También agradezco la ayuda en la localización de los diseños a Rosario Santamaría Almolda, mi discípula y amiga. Asimismo, y desde hace ya muchos años, a Esperanza Navarrete en el Archivo. 
y documentación resultan totalmente dependientes y siempre complementarios entre sí.

No se indicarán aquí detaliadamente los diseños de cárceles localizados en el Archivo y en ese Gabinete de la Academia madrileña, pues a continuación tan sólo se estudiarán los proyectos que se hallan bajo la influencia del panóptico de Bentham, prescindiendo de aquellos otros que siguen la línea tradicional de cárcel como palacio fortificado. Sin embargo, se destacarán de entre ellos varios, como, por ejemplo, los de Juan Soler y Mestres, (1830), José Solano (1831), Juan José Jimeno y Casanova (1833), Fabio Gago (1847), Juan Farelo (1852), Manuel Maffei (1853)... por el interés de las figuras dadas a sus propuestas.

\subsection{Las pruebas para los exámenes de arquitectos y maestros de obras}

Parece imprescindible, antes de analizar los proyectos de cárceles, que de alguna forma siguen el modelo de Bentham, conservados en la Academia como arquitectura sobre papel que a la par es utópica y realizable en lugar concreto, referirse aquí con cierta brevedad y generalizando a los exámenes que los aspirantes a estos títulos realizaban. En este sentido he publicado ya varios artículos en los últimos años sobre la formación del arquitecto académico a finales de la llustración, los planes de estudios que seguían, los tratados empleados, los ejercicios necesarios para acceder a los diferentes títulos de la arquitectura..., a los que me remito para profundizar en lo que aquí sigue ${ }^{20}$.

El aspirante a uno de los grados de arquitecto y maestro de obra debía diseñar una prueba de pensado, que entregaban con la instancia de solicitud correspondierite, como ejercicio previo. Analizada por los profesores integrantes de la Comisión de arquitectura se votaba secretamente sobre su aprobación o reprobación y en el caso de haber sido aceptado se sorteaba en la junta ordinaria siguiente de la Academia tres temas de un libro de asuntos para que el pretendiente eligiera uno. Esta segunda prueba, llamada de repente, se realizaba en la misma Academia, permaneciendo el pretendiente aislado durante diez o doce horas. Si los

20 Una síntesis en: García MELERO, José Enrique, «El arquitecto académico a finales del siglo XVIII". Número monográfico sobre la profesión del artista conmemorativo del décimo aniversario de la revista. En "Espacio, tiempo y forma", serie VII, núm. 10, págs. 161-216. Madrid, Departamento de Historia del Arte, Facultad de Geografía e Historia, UNED, 1997. 
profesores de arquitectura le aprobaban, pasaba a realizar un tercer examen oral, que consistía en contestar a cuantas preguntas y objeciones sobre los planos realizados y asuntos relacionados con la arquitectura le hiciera el tribunal examinador. Sólo en el caso de aprobarlo se le podía expedir el certificado correspondiente.

En realidad, había pocas diferencias formales entre los exámenes que hacían los aspirantes a arquitectos ${ }^{21}$ y a maestros de obras desde la terminación de la Guerra de la Independencia en 1814 y la creación de la Escuela de Arquitectura en Madrid en 1844. Quizá ello fuera uno de los motivos principales, junto con el encargo de obras, en la duras polémicas entabladas entre ambos profesionales de la arquitectura. Sin embargo, se les exigían conocimientos más profundos a aquéllos. Estos últimos eran más prácticos, más concretos, menos ideales. Solían hacer sus diseños de forma simplificada en dos pliegos de papel, donde se incorporaban la planta y la fachada principal, y el corte. Los diseños de los arquitectos eran más numerosos y detallados, pues se incluían las plantas tanto del piso bajo como del principal, los cortes transversal y longitudinal, y las fachadas principal, posterior y laterales. Los informes justificativos de estos últimos también solían ser más minuciosos y extensos. A una introducción sobre la tipología en cuestión y sus relaciones con la función a cumplir más o menos extensa y elocuente, seguía la descripción del proyecto y de los diseños con su forma general y distribución. Por último, se indicaba el análisis del método de construcción, la enumeración y justificación de los materiales a emplear y el coste detallado de la obra.

Las diferencias también venían dadas por los libros de asuntos, pues el redactado para los exámenes de maestros de obras contenían bastante menos temas que el de los arquitectos. Los unos se ocupaban del diseño de las llamadas obras mayores o de consideración y los otros de las menores, aunque los límites entre ambas siempre aparecían algo confusos, tal vez demasiado sutiles. Obviamente se exigía a éstos más conocimientos teóricos que a aquéllos 2 .

21 Un inventario localizando de forma individual los legajos del Archivo de la Academia madrileña, donde se hallan los distintos expedientes e informes facultativos de los aspirantes al títu10 de arquitecto en: SANTAMARÍA ALMOLdA, Rosario, «Bases documentales para el estudio de la teoría arquitectónica en la Real Academia de Bellas Artes de San Fernando (1814-1858)". Espacio, tiempo y forma, serie VII, t. 9. Madrid, Departamento de Historia del Arte, Facultad de Geografía e Historia, UNED, 1996, págs. 219-249.

22 Propuestas de asuntos para disertaciones a fin de acceder los maestros arquitectos a académicos de mérito de arquitectura en AASF: 140/3. 


\subsection{Submodelos del panóptico de Bentham: del panóptico a la cárcel celular}

La influencia del modelo de Bentham es, sin duda, la más perceptible, junto al sistema tradicional palaciego, en todos estos proyectos diseñados como prueba de pensado o de invención para obtener los títulos de arquitecto o maestro arquitecto y maestro de obras en la Academia madrileña. Sin embargo, fue modificado por medio de variantes más o menos importantes, o submodelos, que, aunque empleaban las líneas maestras diseñadas por el jurisconsulto inglés, también proporcionaban ciertas novedades a un doble nivel general y, asimismo, particular. Así, frente a la cárcel panóptica de plan central circular o dodecagonal, se suelen diseñar figuras octogonales, hexagonales y, algunas veces, hasta polilobulares. Pero, además, esta figura se inscribe dentro de una planta, sobre todo, cuadrada y rectangular, al margen del recinto amurallado con su foso y la empalizada previstos por Bentham. Otra variedad muy en uso viene dada por el empleo del semicírculo a modo de semipanóptico, que en ocasiones es doble para diferenciar los espacios dedicados a los hombres y a las mujeres. Suelen unirse ambos semipanópticos por medio de un cuerpo cuadrado o rectangular, donde se sitúan los servicios más generales del presidio.

La proyección de estos otros espacios de planta distinta, normalmente rectangular y cuadrada, con respecto al panóptico, que, como norma, queda inscrito en su interior o se añade de forma semicircular a ambos extremos, obedece, por lo tanto, a la necesidad de disponer de una serie de dependencias de carácter general dentro del recinto de la cárcel. Si éste asume su natural función de lugar de retención vigilada del preso desde la torre, situándose en su contorno las celdas, aquél se emplea para residencia de los guardianes, con la finalidad de ubicar el juzgado y sus correspondientes oficinas, el archivo y la escribanía, a veces para los talleres de trabajo de los reos, para la misma capilla en ocasiones... Viene a actuar, además, como un cuerpo regulador del conjunto, que une al tiempo que separa, y hasta de desahogo del mismo, dando lugar a otro patio.

El modelo proporcionado por el jurisconsulto inglés no se reflejó, por lo tanto, con toda perfección en los proyectos diseñados por los aspirantes a los distintos grados de la arquitectura de la Academia, como tampoco se hizo en la realidad concreta de los edificios construidos, que optaron por esta propuesta siempre con una relativa mayor o menor fidelidad. Hubo, así, varios submodelos diferentes más o menor ortodoxos o heterodoxos con el sistema, o esquema ideológico, ideado: casi tantos como proyectistas. De su plan se tomaron las líneas esenciales, que reflejan su filosofía jurídica cobre la cárcel 
traducida a un nivel arquitectónico, tratando de completarlas de algún modo. El círculo o dodecaedro de Bentham, como contorno general, fue reemplazado en ocasiones por otras figuras de tipo central, como, por ejemplo, el octógono y el hexágono, y hasta por la forma de auténtico trébol. Además, el panóptico aislado de Bentham se inscribió racionalizándose funcionalmente en una figura general, ya cuadrada, ya rectangular para satisfacer las necesidades comunes, con la finalidad de ubicar los servicios directivos y administrativos del presidio.

Hay que destacar aquí que se formó otro modelo, también seguido en la Academia, procedente de la prisión de Filadelfia en calidad de ejemplo más significativo, donde se estableció una auténtica síntesis entre los dos pardigmas modernos considerados entonces más adecuados para esta tipología: el correccional de Gante y el panóptico de Bentham. Así, resultó una cárcel de crujías radiales, que se aproxima aún más a los proyectos de hospitales de pabellones aislados, propuestos por Petit y por Poyet en Francia. Del punto central de una planta general circular, o semicircular, o dodecagonal, u octogonal y o hexagonal parte una serie de crujías radiales, dispuestas siempre simétricamente a intervalos regulares y en un número distinto, que dejan en el centro un espacio también central de diferente figura, donde se sitúa la torre de vigilancia. Sin embargo, tal torre parece perder en este nuevo modelo su función de lugar de vigilancia de las celdas, pues quedan dispuestas en diagonal por las crujías. Se minimiza de esta manera gran parte de la perspectiva visual. Ahora lo que se vigila desde lo alto son, sobre todo, los patios formados entre los pabellones radiales.

Así, Juan Soler y Mestres, aspirante al título de arquitecto, abrió en 1830 la serie de variantes del panóptico de Bentham en la Academia madrileña con un proyecto realmente espectacular y de gran belleza, que fue aprobado por los profesores de la Comisión de arquitectura ${ }^{23}$. Su submodelo responde a la planta general rectangular, que contiene inscrito un panóptico casi circular total, porque hizo rectos lateralmente dos de sus lados. Entre él y el rectángulo general situó dos patios asimismo rectángulares. Pero este modelo entonces tan novedoso en España también fue asumido por otro pretendiente al título de arquitecto en 1831: el madrileño josé Solano, Marqués de Socorro, en su casa de corrección de forma panóptica.

Solano diseñó otro submodelo del panóptico: articuló tres cuerpos de forma simétrica, de los cuales el central era cuadrangular y los dos extremos

23 Cárcel para Barcelona. 1830. Informe de Juan Soler y Mestres en AASF: leg. 9-2/2. Diseños del proyecto en AASF: A-954-957. 
semicirculares. Obedece a la idea, ya indicada antes, de crear un cuerpo nuclear de servicios generales, que relaciona, uniendo y separando a la vez, dos semipanópticos. La disposición y distribución responde a la necesidad de la clasificación de los presos, ahora principalmente por sexos: en el lado derecho situó a los hombres y en el izquierdo a las mujeres, tal y como también se hacía en los hospitales proyectados entonces y siguiendo la tradición ${ }^{24}$ (lám. 6).

Tal submodelo de panóptico del Marqués de Socorro, que incluía en los extremos dos medios panópticos, fue seguido también por el zaragozano Juan José Jimeno y Casanova, discípulo a la vez de la Real Academia de San Luis y también de Antonio Celles y Azcona en Barcelona, en 1833; pero, asimismo, estableció una variante formal: el cuerpo central, que sirve de nexo, es ahora un rectángulo de núcleo distinguido por contener la capilla, a

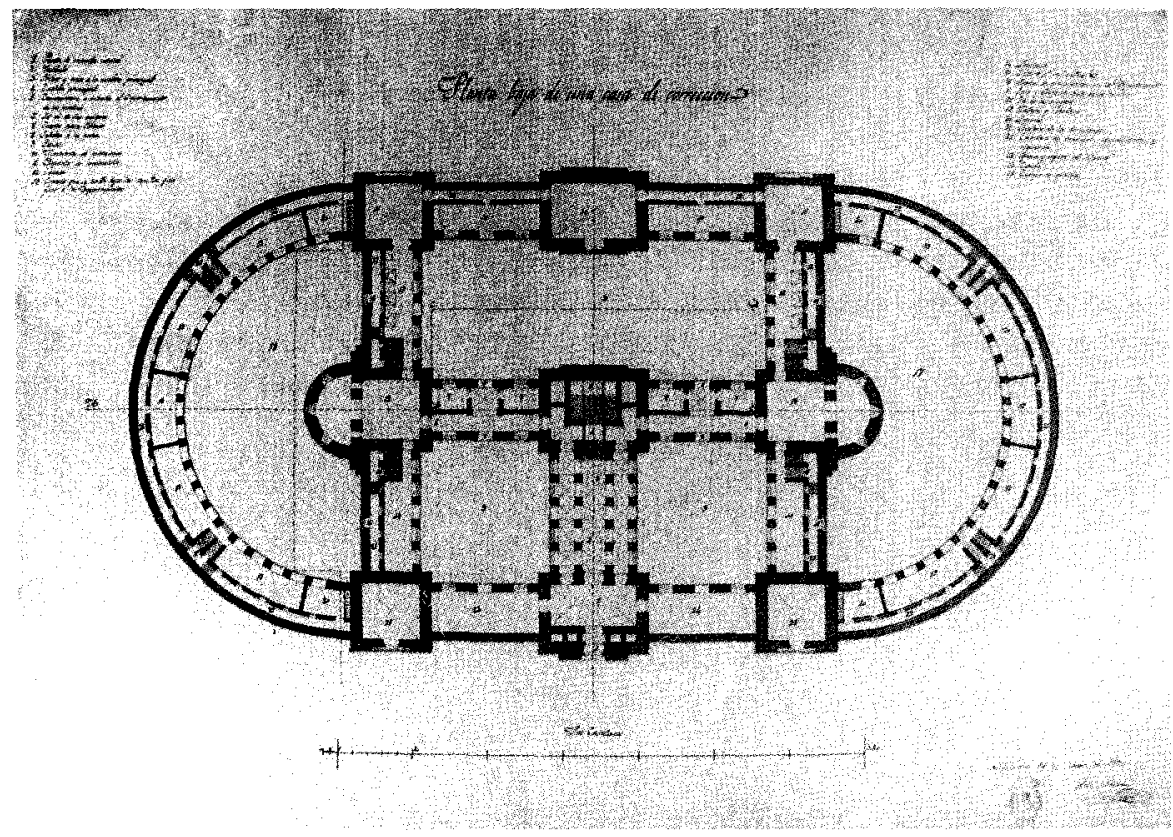

Lám. 6. Planta del proyecto de casa correcional en forma de panóptico del madrileño José Solano, Marqués de Socorro. 1831.

24 Informe facultativo sobre la disposición y coste de una Casa de Corrección en forma Panóptico de José Solano, Marqués de Socorro, en AASF: leg. 9-6/bis. Datado en Madrid, 15 de enero de 1831. Los diseños del proyecto en AASF: A-959 
cuyos lados menores se unen dos semipanópticos semicirculares. De nuevo diferenciación de presos por sexo; mas la figura también permitía distinguirlos según el tipo de delito cometido, tal y como recomendaba la jurisprudencia de la época, $y$ hasta conceder espacios privilegiados a personas de alguna consideración social ${ }^{25}$.

Otro submodelo del panóptico de Bentham, más complejo aún, puede hallarse en el proyecto de una cárcel para la ciudad de San Sebastián del futuro arquitecto Joaquín Ramón de Echeveste, fechado ya en 1839. No obstante, presenta cierta semejanza con los planes del Marqués de Socorro y de Juan José Jimeno en su figura general rectangular, que aquí es el resultado del encuentro de un gran cuadrado central con dos estrechos rectángulos en los extremos ${ }^{26}$. Sin embargo, en lugar de emplear dos semipanópticos laterales, inscribe uno completo totalmente circular en ese cuadrado, destinado a correccional (lám. 7). La unión de todas estas figuras - cuadrado central, círculo inscrito en él y rectángulos alargados laterales- le permite una mejor distribución del edificio, pues concede a cada una de ellas distintas funciones complementarias en el conjunto. Así, el rectángulo delantero es el lugar de la audiencia y de las oficinas, y el posterior lo dedicó a correccional femenino, situando en él un gran lavadero para que las mujeres trabajaran. Pero, además, Echeveste, quien buscaba regularidad y conjunción, logra idear una pequeña urbe encerrada entre los muros, que contiene numerosos patios arbolados, como si se tratasen de jardines.

Ya en 1846, el riojano Maximiliano Hijón empleó otro complejo submodelo celular, que parece seguir de alguna forma la propuesta de Bentham, aunque inspirándose ahora en el atlas carcelero de Ramón de la Sagra de 1843. En el fondo esta variante admitida es una modificación racionalista del panóptico, que hace radial celular - de celdas individuales-, sin crujías al modo de los pabellones aislados ${ }^{27}$. Su planta no es ni dodecagonal ni tampoco circular, tal y como propuso el inglés, sino en la totalidad de su perimétro un polígono octogonal irregular en tres de sus lados para trazar uno de ellos más alargado con la disminución de la longitud de los otros dos, donde situó la entrada. El panóptico propiamente dicho tiene forma de trébol regular con un patio concéntrico, que como proyección suya define

25 Cárcel o Casa de detención. Informe facultativo de Juan José Jimeno y Casanova en AASF: leg. 19-2/2. 1833. Los diseños del proyecto en AASF: A-969-971.

${ }_{26}$ Cárcel para la ciudad de San Sebastián. 1839. Informe de Joaquín Ramón de Echeveste Mendiburu en AASF: leg. 11-1/2. Los diseños del proyecto en AASF: A-983-986.

27 Proyecto de una cárcel según el sistema celular para la ciudad de Logroño. 1846. Informe facultativo de Maximiliano Hijón en AASF: leg. 13-5/2. Diseños del proyecto en AASF: A-992-993. 


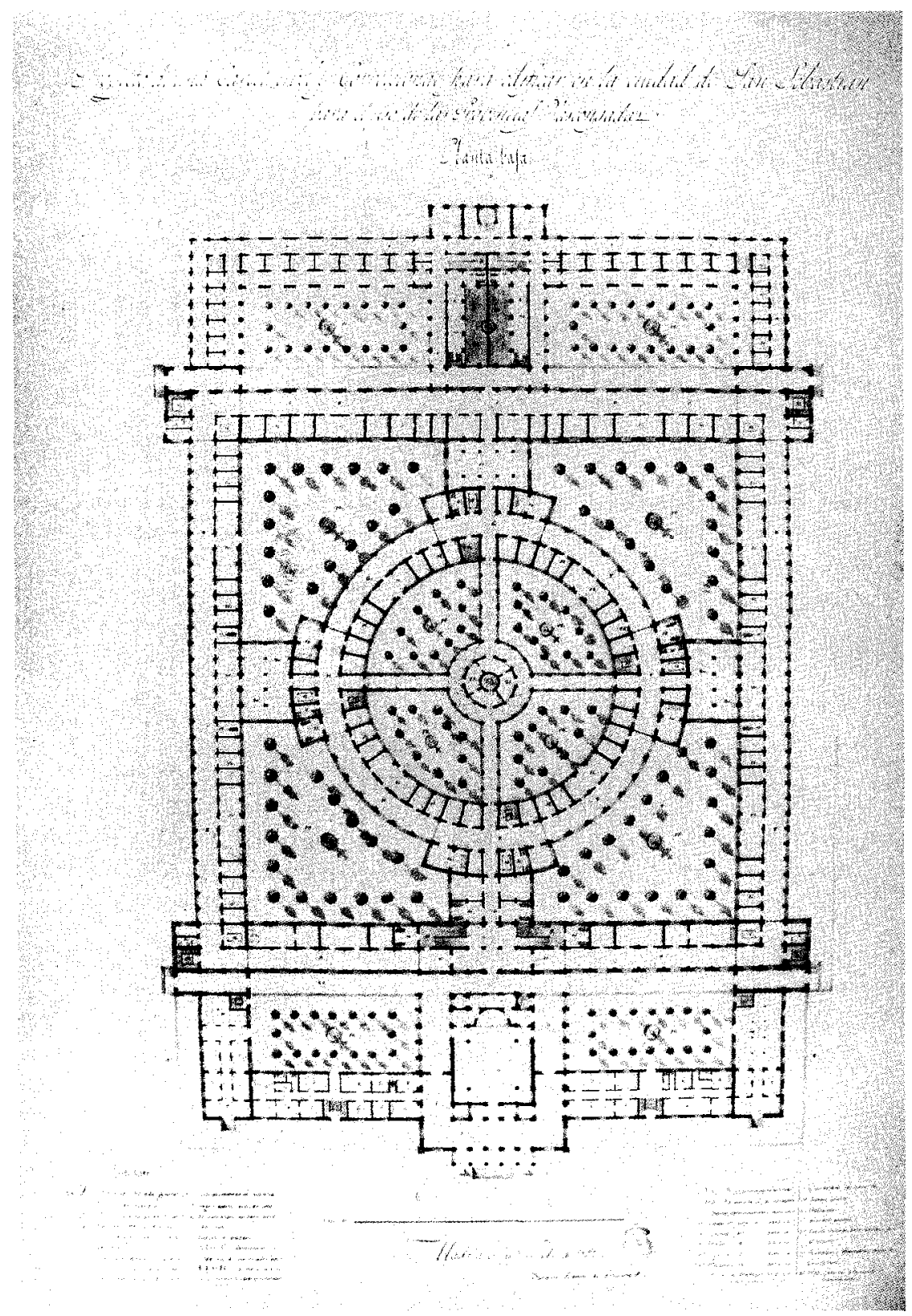

Lám. 7. Proyecto de cárcel para San Sebastián de Joaquín Ramón de Echeveste Mendiburu. 1839. 
igual figura. En medio, en la torre central situó un templete dórico, que cita el sistema clásico con la utilización de este orden, encima de la habitación del alcaide. A cada fila de celdas en altura corresponde un trozo del patio situado entre ellas y el paseo de ronda. Se dispone de modo radial y se baja a él por una escalera de caracol (lám. 8).

Fabio Gago Muñoz, granadino ${ }^{28}$, estableció en 1847 otro modelo diferente casi fabril, al conceder a los talleres una gran importancia en su presidio, tanta, o más, que al mismo panóptico, hasta el punto que su cárcel se convierte en una auténtica «f́brica». No hay que olvidar que el proyecto de Bentham también era aplicable a todas aquellas industrias, donde había que controlar visualmente el trabajo realizado por los obreros. El plan de Gago se podría considerar, desde esta perspectiva, como un triple panóptico. La planta general es un gran cuadrado dividido en tres partes, siendo la central de doble tamaño que las laterales. Las dos de los extremos se dedican a los talleres ${ }^{29}$. El panóptico propiamente dicho ocupa el centro geométrico del conjunto y exteriormente es un octógono regular, mientras que su interior al patio resulta fiel con la figura circular propuesta por Bentham. Este sistema obedecía a la idea de mantener aislados a los presos en las horas de descanso y relacionarles entre sí en el trabajo por necesidad obvia (lám. 9).

El proyecto final de carrera de 1852 para cárcel de partido del madrileño Juan Farelo y Díaz, formado ya en la Escuela Especial de Arquitectura, tiene forma semicircular, aunque inscrita en un rectángulo general, similar a un semipanóptico, pero también celular. Sin embargo, se aleja ya bastante del sistema de Bentham, tanto como se acerca a la cárcel de Filadelfia, porque dispone las celdas no en torno al patio central para que los presos sean siempre vistos, sino a lo largo de seis crujías radiales que forman entre sí cinco patio interiores porticados triangulares con uno de sus lados curvo ${ }^{30}$. Ubicó los servicios generales de la cárcel, así como los talleres, en el lado recto de la fachada con puerta de ingreso. No obstante, diseñó otro patio, el principal, central y porticado de forma semicircular, que, además de servir de desahogo, dedica al servicio religioso y a la inspección. Su modelo de crujías radiales obedecía a la idea de lograr una

28 Fabio Gago MuÑoz nació en Granada el 23 de septiembre de 1819, siendo hijo de José, capitán de los ejércitos nacionales. Estudió en la Universidad Literaria de esta ciudad entre 1835 y 1837.Trabajó como aparejador con el arquitecto académico Baltasar RoMERo. Completó sus estudios en Madrid durante cuatro años.

29 Presidio con fundición de cañones con destino a Sevilla. 1847. Informe facultativo de Fabio GAGo en AASF: leg. 14-1/2bis. Los diseños del proyecto en AASF: A-996-999.

30 Cárcel de partido. 1852. Informe facultativo de Juan FARELO y DíaZ en AASF: leg. 14-3/2. Los diseños del proyecto en AASF: 1007-1010. 


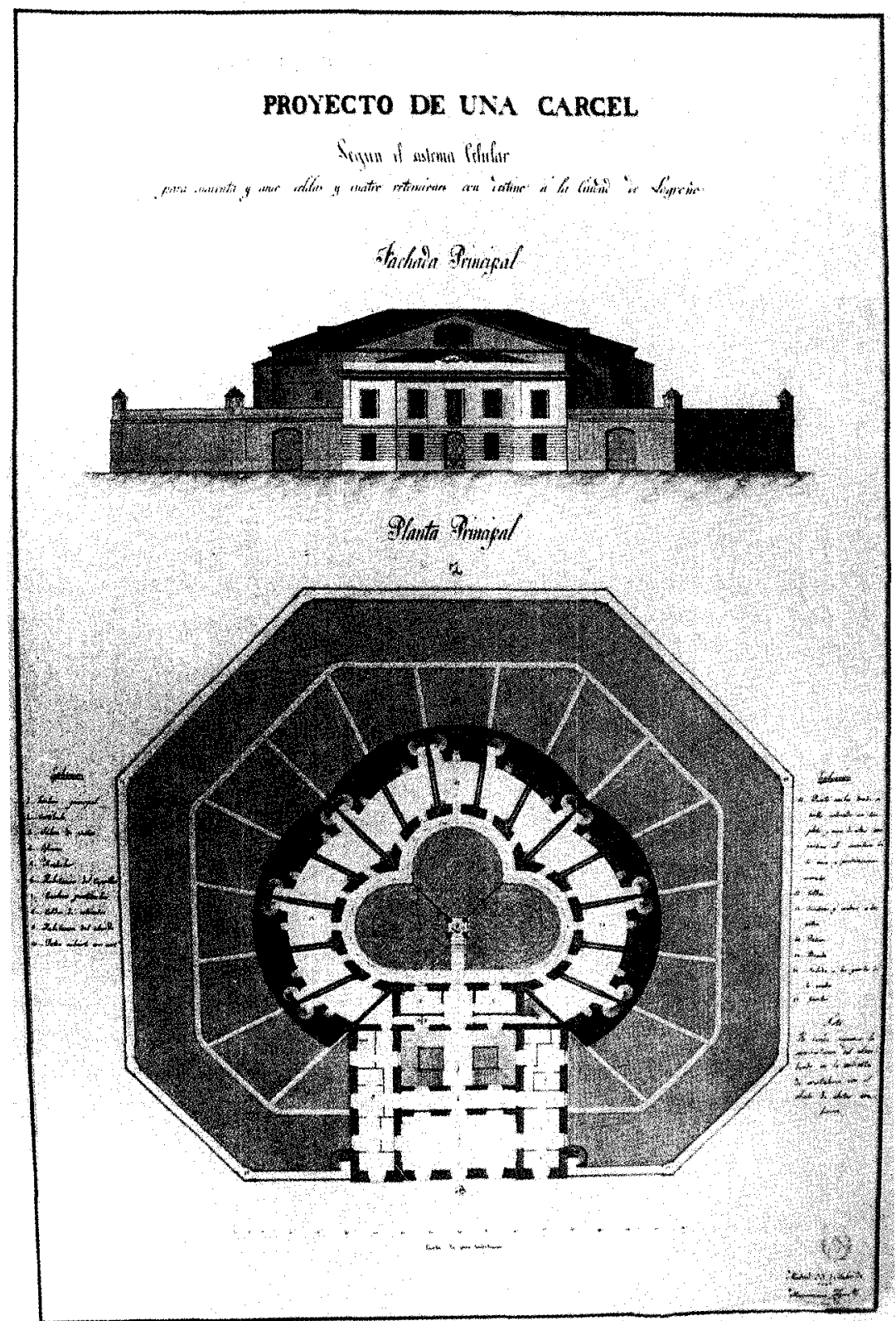

Lám. 8. Proyecto de una cárcel según el sistema celular para la ciudad de Logroño de Maximiliano Hijón Ibarra. 1846. 


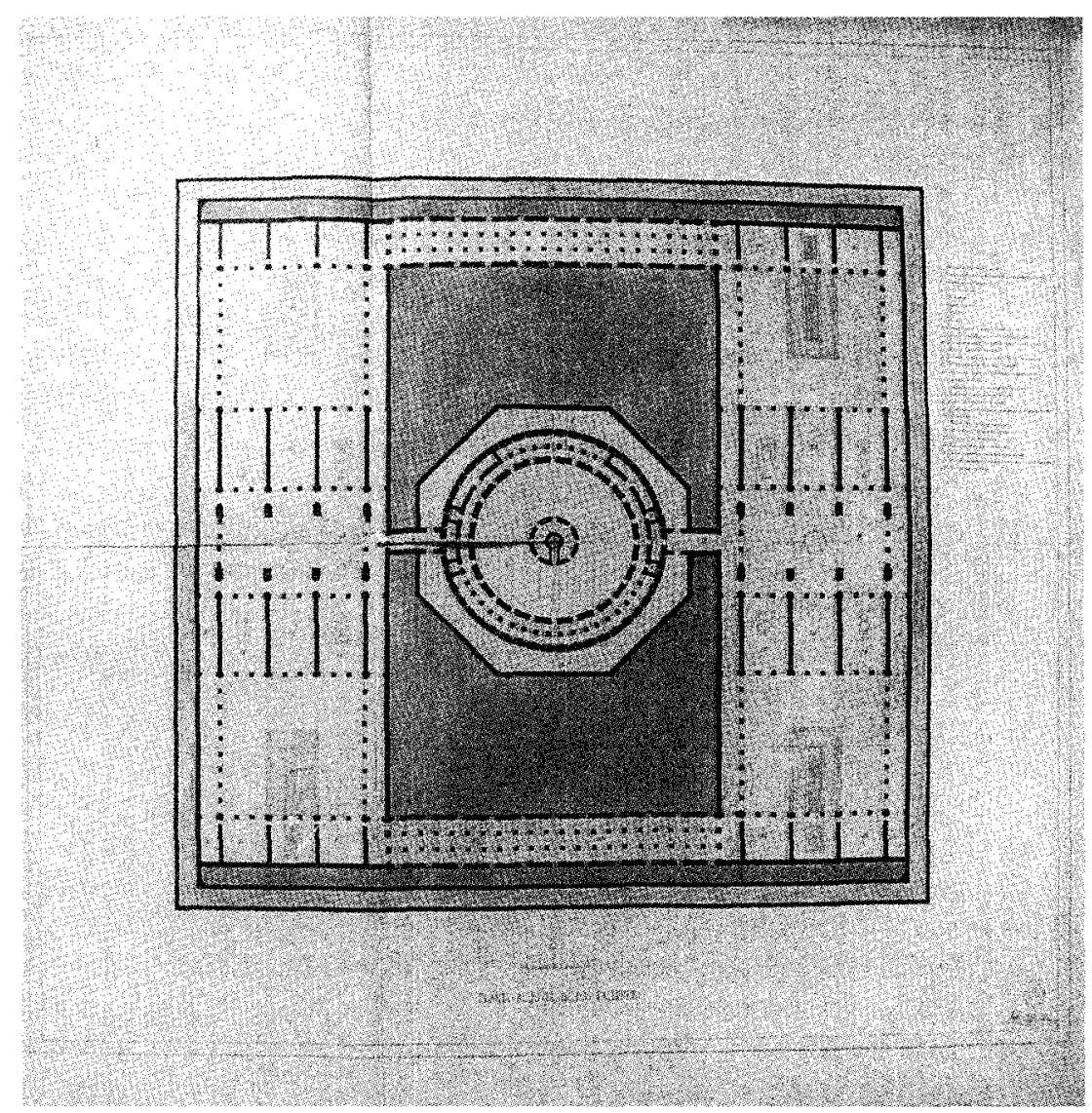

Lámina 9. Proyecto de planta de cárcel para Barcelona de Juan Soler y Mestres, discípulo de Antonio Celles. 1830.

clasificación adecuada de los presos según se tratara de acusados o sentenciados, bien por delitos leves o por graves, sección de incomunicados y jóvenes menores de 15 años. Así, el sistema de Farelo sigue de forma referencial a Bentham; pero definitivamente es ya celular radial.

Algo más ortodoxo con el sistema del jurista inglés quizá sea el proyecto de Manuel Maffei Bozal ${ }^{31}$. Incluye un panóptico de forma de dodecaedro re-

31 Esta memoria sobre el proyecto de un correccional, fechada en Madrid el 11 de marzo de 1853, forma parte del ejercicio de reválida para obtener el título de arquitecto según el artículo 12 del reglamento de la Escuela Especial de Arquitectura de esta Corte. 
gular inscrito en un rectángulo; pero con tres crujías radiales entre ambas figuras, motivo por el cual también parece citar el penal de Filadelfia. Sin embargo, hay otra diferencia manifiesta con relación al sistema de Bentham, pues la torre de control no se sitúa en el centro del patio. En su lugar los presos son vigilados desde la entrada de las galerías laterales por una sola persona en cada piso. El proyecto fue presentado en 1853. El patio interior es porticado ${ }^{32}$. El perímetro rectangular se corresponde con los servicios directivos y administrativos del presidio. Entre las crujías radiales - dos de ellas con celdas a ambos lados de un pasillo central- y el rectángulo se constituyen cuatro jardines o huertas de diferente forma de dos a dos, que sirven de recreo a los presos según el sistema de clasificación.

No se desea terminar de analizar la influencia del panóptico de Bentham en los proyectos académicos sin referirme, aunque sea con brevedad y retrocediendo en el tiempo de este análisis tipológico cronológico hasta 1838, a la cárcel y presidio ideada por el barcelonés de Igualada Miguel Geliner y Gelma según los principios de disposición, distribución, comodidad, conveniencia y salubridad ${ }^{33}$. Ello es así porque considero que su panóptico, de una planta tan bella como abstracta, significa el desbordamiento máximo de la idea del panóptico en gran medida ${ }^{34}$. De aquí que su prueba de pensado no resultara admitida por la Academia, pues presentaba varias incongruencias como, por ejemplo, la compartimentación del espacio visual por medio del trazado de ocho crujías radiales, dos de ellas con celdas. De este modo también la vigilancia se especializa en un lugar concreto de los ocho compartimentos, que quedan entre esas crujías. Quizá los profesores vieran los diseños como extremadamente ideales. Además, no justificó su proyecto en el informe con la necesaria suficiencia, generalizando demasiado y de una forma un tanto retórica.

\subsubsection{La originalidad del proyecto de Juan Soler y Mestres}

El primero en el tiempo de todos estos proyectos de cárcel con forma panóptica, hallado en el Gabinete de dibujos de la Academia madrileña, es

32 Un correccional. 1853. Informe facultativo de Manuel MAFFEI BozAL en AASF: leg. 14-5/2. Los diseños del proyecto en AASF: A-1011-1015.

${ }_{33}$ Tal proyecto fue reprobado por la Comisión de Arquitectura. Geliner tenía entonces 26 años. Había sido discípulo de la Escuela de la Lonja de Barcelona, donde estudió con José Oriol la arquitectura civil entre 1830 y 1838 y matemáticas con Antonio CELLES, su director. Posteriormente presentó otros diseños como prueba de invención: una casa aduana, lavaderos para una capital de provincias y una iglesia parroquial. Fue admitido a examen con votación empatada en esta ocasión: tres votos a favor y otros tanto en contra. Se le aprobó el 14 de noviembre de 1838.

34 Cárcel y presidio correccional. 1838. Informe facultativo de Miguel Geliner y Gelmá en AASF: leg. 10-3/2 bis. Está fechado el 10 de septiembre de 1838. Los diseños del proyecto en AASF: A-981. 
el del barcelonés Juan Soler y Mestrer, discípulo de Antonio Celles en el Consulado de Comercio de Barcelona ${ }^{35}$. Realizado en 1830 encarna todas las novedades posibles en su tiempo, prediciendo a modo de síntesis las líneas maestras de la arquitectura decimonónica siguiente. Su propuesta es a la vez clásica, científica y moderna por el empleo de ese modelo del jurista inglés y hasta neomedieval en su exterior con sus cuatro torres ciclíndricas, que paradójicamente sin distar de ese clasicismo se acerca al gótico (lám. 10). De todo ello resulta por un lado un cierto historicismo manifiesto; mas también una actitud totalmente ecléctica por el empleo de este conjunto de componentes. Pero, además, su idea parece totalmente funcional y en la utilización de las figuras geométricas puras hace causa común con la arquitectura parlante francesa, pudiéndosele considerar en cierto modo hasta como un auténtico visionario, que muy poco o nada

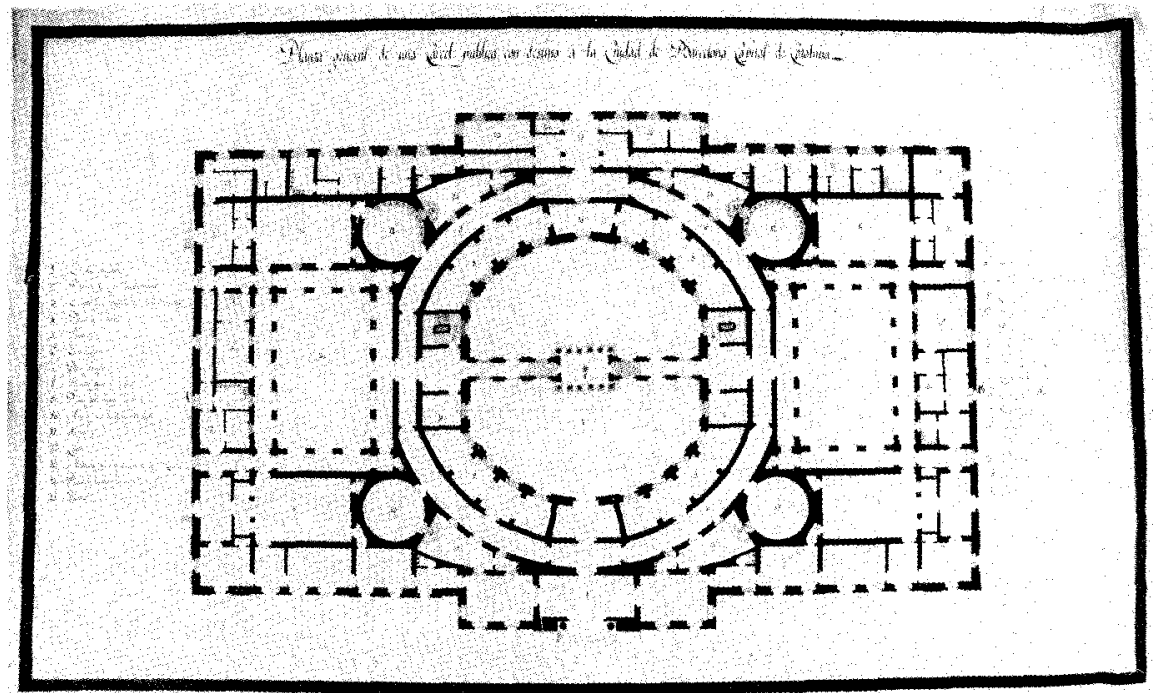

Lám. 10. Proyecto de planta de cárcel para Barcelona de Juan Soler y Mestres, discípulo de Antonio Celles. 1830.

35 Este proyecto de Soler ha sido reproducido en el catálogo de una muestra de los fondos de los proyectos existentes en esta sección de dibujos de la Academia, que motivó una pequeña exposición: TIPOLOGÍAS arquitectónicas. Siglos XVII y xIX. Fondos del Museo de la Real Academia de Bellas Artes de San Fernando. Madrid, Real Academia de Bellas Artes de San Fernando Comunidad de Madrid, 1999, pág. 31. Véase el prólogo de Antonio Bonet Correa titulado «Arquitectura de papel». Tipos y modelos de edificios en la Real Academia de Bellas Artes de San Fernando, págs. 9-14. 
tiene que envidiar a estos arquitectos galos. Por si fuera poco, establece una síntesis de influencias al tomar elementos de la arquitectura italiana, francesa e inglesa. La cita directa del clasicismo se halla en el templete dórico al estilo del teatro Marcelo, que sitúa en el centro geométrico del patio del panóptico, y también en el atrio de dos columnas al estilo de Phaestrum de la fachada principal ${ }^{36}$.

Tal proyecto de Soler habla bien a las claras del estado de la arquitectura catalana salida de la dirección de Celles al cumplirse el primer tercio del siglo xix y, en concreto, de esa Escuela del Consulado de Comercio de Barcelona ${ }^{37}$. Certifica también que estos arquitectos catalanes tenían puesta la mirada en la modernidad y, en concreto, en Francia, mientras que algunos de los profesores de la Academia madrileña todavía continuaban en la añoranza del nuevo clasicismo, quizá tan utópico, y en el empleo todavía de un repertorio tradicional de modelos de cárceles.

\subsubsection{Las fachadas de las cárceles}

Parece haber un acuerdo tácito entre la totalidad de los futuros arquitectos y maestros de obras, que se examinaron en la Academia, a la hora de diseñar las fachadas un tanto «terribles» de sus proyectos, aunque se perciban algunas diferencias peculiares en determinados diseños y unas pocas sean algo más «dulces» que las otras muchas. También parten de la idea del palacio y del cuartel, tanto los modelos tradicionales como éstos más modernos al estilo de Benthan, hasta que se logra poco a poco una representación específica de la cárcel, muy escenográfica, que la hace diferenciarse de ellos. Así, la mayoría de los pretendientes a titularse coinciden en sus escritos en una premisa previa muy de la época: la fachada debería anunciar la función peculiar del edificio, o lo que es lo mismo, el aspecto exterior no desmentirá nunca su destino. En este sentido parece hallarse casi siempre presente el modelo de cárcel parlante de Ledoux, al que a veces se superpone el submodelo de Durand, que significa su difusión con cierta variante.

Ante todo se deseaba alcanzar la severidad y la desornamentación. Francisco María Aguirre, tal y como la mayoría afirma, así lo escribía en

\footnotetext{
36 Informe de Juan SOLER y MESTRES en AASF: leg. 9-2/2.

37 Juan SOLER y MESTRES había nacido en 1795 en Barcelona, siendo hijo de Tomás SOLER y FerRer, arquitecto del Real Patrimonio de Barcelona y de la Real Junta y Consulado de Comercio. Su tío Francisco Soler era también maestro de obras. Su abuelo proyectó el edificio de la Real Casa de la Lonja, destinada a Bolsa de Barcelona. Habia estudiado en la Escuela gratuita de Arquitectura de la Ciudad Condal entre los años 1817 y 1820. Cursó las matemáticas con Antonio Celles.
} 
1826: la cárcel tenía que "pintar en la imaginación del hombre el odio al delito y el temor a ser conducido a este edificio" ${ }^{38}$. De la fachada principal -que deberá ser «sencilla», pero «robusta», «grave», «imponente» y "elocuente» como la parte más noble del edificio- tan sólo suele destacarse su pórtico y el centro de su planta principal, donde muchas veces se aloja el tribunal de justicia y en algunas pocas ocasiones la misma capilla. Sus muros son de un grueso superior al necesario, pues hay que evitar las evasiones en todo lo posible, y suelen inclinarse suavemente para adquirir un aspecto más sólido y terrible. Se admiten pocas decoraciones inútiles con la finalidad de ser congruentes con su destino. Sin embargo, se puede jugar con los volúmenes, con la construcción de algunos cuerpos en avance y de otros en retroceso para crear claros efectos de luces y de sombras, que proporcionan un ambiente adecuado y quizá hasta la sensación irreal de un cierto ornato sorprendente. En ocasiones, la planta baja se almohadilla, o tan solo sus extremos, o su portada, y se insinúan torres la mayoría de las veces ficticias, que aluden a sus orígenes en los castillos. También se alternan formas dispares en los pocos y escasos huecos al exterior: semicírculos en la planta baja o pequeñas ventanas cuadradas, rectángulares en la principal, hasta falsas meramente decorativas... Suelen llevar guardapolvos, que vienen a ser exiguos ornatos camuflados. Algunos de estos presidios manifiestan exteriormente la existencia de la capilla por medio de privilegiadas cúpulas de media naranja. Así, casi todo ornato queda reducido al empleo del pórtico de la entrada, por lo general, la única, tal y como recomienda la jurisprudencia, y en el uso bastante escaso, para lo que entonces solía ser común, de los órdenes arquitectónicos. Éstos debían ser los más austeros posibles y, así, se eligen o el dórico o el toscano.

No obstante, aunque los futuros arquitectos y maestros de obras coincidiesen entre sí en muchos aspectos tanto en sus diseños como en los contenidos de sus informes, no por ello dejaron de dar un aspecto un tanto personal a los exteriores de sus cárceles, presidios, correccionales..., aspecto que también dependía de su misma misión secundaria o circunstancial.

Soler resulta, tal y como ya se indicó antes, un caso excepcional de elocuencia formal tanto de la planta como de su distribución y aspecto exterior: su cárcel para Barcelona semeja ser a la vez castillo, fortaleza, cuartel y cárcel. El panóptico propiamente dicho se eleva, asomándose, por encima de un más edificio bajo. En su informe aludió con cierta ex-

38 AGuirRe, AASF: leg. 68-6/4. 
tensión a la decoración exterior de éste por medio de un zócalo circundante, que quedaba interrumpido en el frente principal por una escalinata de cinco gradas saliente en el cuerpo adelantado del centro. También circuyó todo el edificio con un cornisamento. La entrada principal consta de un pórtico adelantado con dos columnas de orden de Paestum o Posidonia. Encima de su arquitrabe apoyó un arco, coronado por un frontón. A ambos lados del mismo dispuso sendas ventanas cuadriláteras con sus correspondientes guardapolvos. Situó un cuerpo saliente almohadillado a los extremos de las dos fachadas laterales, en los que figuró unos arcos y una ventana (lám. 11).

\section{Tadiati liffoul}

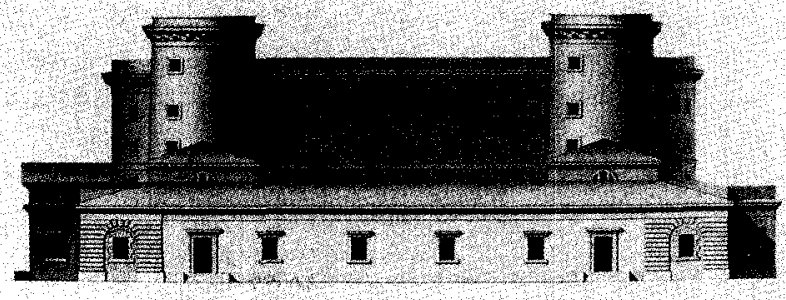

i. . H

Lám. 11. Alzado del proyecto de cárcel para Barcelona de Juan Soler y Mestre. 1830.

José Solano ${ }^{39}$, discípulo de la Academia y de Custodio Teodoro Moreno, logró también reflejar en el proyecto el destino de su correccional con doble semipanóptico, separador de sexos. Estaba cercado por un muro. Dispuso un basamento general de seis pies de sillería y un revesti-

39 José Solano, Marqués de Socorro y Conde del Carpio, fue aprobado como arquitecto en la junta ordinaria del 13 de marzo de 1831. Era madrileño y entonces tenía 28 años. Había asistido al estudio de Custodio Moreno durante cinco años. AASF: 9-6 bis/2. 
do de almohadillado hasta el piso principal en la parte correspondiente a la planta rectangular. Las columnas de la fachada eran de piedra y los cimientos de mampostería. La principal reflejaba con elocuente fidelidad la planta y la función de cada uno de sus espacios. Así, avanza ligeramente las tres crujías de ese cuerpo rectangular, abriéndose una puerta en cada una de ellas: las dos laterales de acusado arco y recta la central, sobre la cual dispuso dos columnas entre sendas pilastras para destacar el espacio destinado a la sala de justicia. Al exterior se perciben las formas semicirculares de ambos semipanópticos con toda rusticidad.

Juan José Jimeno y Casanova ${ }^{40}$ propuso una fachada principal bastante semejante a la de Solano, pues su planta era muy similar. Deseaba que fuese tan "sencilla» como «imponente», pues «el carácter del edificio debe manifestar clara e indistintamente su destino» ${ }^{41}$. Ello se debía conseguir por la forma, disposición y decoración tanto del exterior como del interior. Así, diferenció en ella la parte central de función general, correspondiente al lado mayor recto, donde se sitúa la audiencia en su piso principal, que ennoblece con cinco arcos entre pilastras. A esta zona central la concede un cierto carácter más representativo casi de palacio público. Sin embargo, dio la mayor austeridad posible a los dos extremos semicircular, los semipanópticos, estancia aislada de castigo de los presos. Entre la parte central más noble y general, y éstos sitúo sendas torres en realce y sobresaliendo en altura al resto del edificio. En lo alto de la entrada dispuso un escudo real. Almohadilló todo el piso bajo, donde se abren pequeñas ventanas semicirculares a lo largo de toda la fachada.

Miguel Geliner fue tan sólo algo retórico en la portada de su fachada de dos pisos, casi tanto como a la hora de diseñar su perfecto y complejo panóptico interior, quizá tan abstracto. Destacó el ingreso en forma de templete elevado sobre gradas con dos series de sendas columnas, friso y frontón triangular, y la torre de vigilancia y capilla central. Insinuó en el exterior las complejas ocho crujías internas con tejados a dos aguas, que

40 Juan José JIMENo era natural de Zaragoza, donde nació el 8 de marzo de 1806, siendo bautizado en la iglesia de San Miguel de los Navarros. Su instancia solicitando ser admitido a examen para obtener el título de maestro arquitecto está fechada el 22 de marzo de 1833. El presbítero Isidro Dolz, académico de honor de la Real Academia de San Luis de esta ciudad y catedrático de matemáticas, certificó que había estudiado durante cuatro años en la cátedra establecida en la Real Sociedad Aragonesa. Fue discípulo de Antonio Celles en la Escuela de Barcelona. Aprobó los exámenes para lograr el título de arquitecto en la junta ordinaria del 10 de noviembre de ese año de la Academia madrileña. En 1844 obtuvo el grado de académico de mérito por la arquitectura, disertando sobre la mejor forma de un teatro para una gran ciudad o Corte (AASF: $44-4 / 1$ ).

41 AASF: 10-2/2. En el fol. 2 anv. de su informe facultativo. 
avanzan ligeramente y se elevan otro piso más sobre el conjunto. Multiplicó los huecos rectángulares con guardapolvos.

Joaquín Ramón Echeveste ${ }^{42}$ fue clásico en su concepción citando de alguna forma la Cárcel de Corte; pero demostrando toda la complejidad de su interior en el exterior. Así, afirma que "su destino excluye todo ornato inútil, un aspecto sencillo y respetable por su masa es lo que mejor conviene a este edificio» ${ }^{43}$. En su fachada destacan las cuatro torres de las esquinas del edificio general, sobresaliendo sobre ella la superficie circular del panóptico interior. Tan sólo destaca en esta línea de austeridad el pórtico general espacioso con una columnata hexástila de entrada única con escalinata, tan sencillo como majestuoso. Como elemento escultórico ornamental propuso que a derecha e izquierda de la entrada se colocaran dos estatuas representándose dos jueces sentados con los atributos de la ley y de la justicia. Hay sendas puertas falsas correspondientes con la habitación del inspector general y del alcaide para su uso exclusivo El recinto del edificio está circundado por un muro de cerca y un foso a su pie, para evitar toda tentativa de evasión y de comunicación con el exterior.

En esta línea se halla Hijón con su original panóptico de planta en forma de trébol con cuarenta y cinco celdas ${ }^{44}$. Su presidio manifiesta exteriormente su planta central octogonal y es muy austera y simple en extremo, anunciando a la perfección su destino. La diseñó de forma robusta y sin ninguna retórica. Sobre el zócalo superior de la fachada principal situó un acroterio, donde ideó colocar, como único motivo decorativo, un grupo escultórico, que representase dos matronas abrazando a la Justicia y a la Verdad. La fábrica es de ladrillo, excepto el zócalo de cantería lisa. Así, tan sólo se destaca la crujía de entrada, pues el resto constituye un muro liso, tras del cual está el paseo de ronda, con torretas de vigilancia en cada ángulo sobre pilastras.

42. Joaquín Ramón de ECHEVESTE MENDIBURU era vecino de San Sebastián, donde nació el 11 de abril de 1805. Había estudiado en la Academia de Náutica del Consulado de esta ciudad. Trabajó como ayudante de Pedro Manuel de Ugartemendía en las obras de reconstrucción de San Sebastián y en las de caminos de la provincia de Guipúzcoa. También colaboró con Mariano José de Lascuraín, académico de mérito por la Real Academia de San Fernando. AASF: $11-2 / 4$.

43 AASF: 11-1/2. Su informe está datado el 30 de noviembre de 1838. Fue aprobado en la junta ordinaria de la Academia del 27 de enero de 1839.

44 Maximiliano HiJón IBARRA, natural de Logroño, había nacido el 21 de febrero de 1820. Era hijo del maestro de obras Juan Hijón, entonces ya fallecido. Estudió primero matemáticas en el Instituto Riojano, después en los Estudios Nacionales de San Isidro de Madrid entre 1843 y 1845 y en el Conservatorio de las Artes de esta ciudad con Ángel Riquelme. Acudió durante tres años a la Academia madrileña. Fue discípulo de Matías Laviña y había asistido al estudio de arquitectura de Wenceslao Gaviña. 
A Gago no le faltó originalidad y simplicidad en su idea: el exterior refleja la finalidad de cárcel tan industriosa a la que iba destinada. En una época tan romántica de revolución industrial resulta una elocuente mezcla de taller y presidio, aunque también consiguiera, por desgracia, esa imagen tan penosa del trabajo, que es aún más doloroso en esas condiciones existenciales de reclusión Los presos solo vivirían para realizar cañones para el ejército. Su proyecto pretendía proporcionar al gobierno grandes ahorros, pues intentaba que sustituyera la fundición de cañones entonces existente en Sevilla. Pensaba que ésta resultaba antieconómica debido a su mala disposición y a los excesivos jornales de los obreros, motivo por el cual quiso sustituirles por presos. De aquí que ubicase su prisión junto al río Guadalquivir a fin de que sirviera de embarque y conducción tanto de los materiales en la fabricación como de transporte de todos los arsenales de la artillería destinada a la Marina. Cada taller, existentes a ambos lados del panóptico, estaría destinado a una especialidad militar: el uno a la fabricación de cañones de hierro de la Marina y el otro para los de bronce al servicio del ejército (lám. 12).

En este breve, pero creo que significativo, resumen de análisis cronológico o evolutivo se puede percibir esa variedad de fachadas dentro de

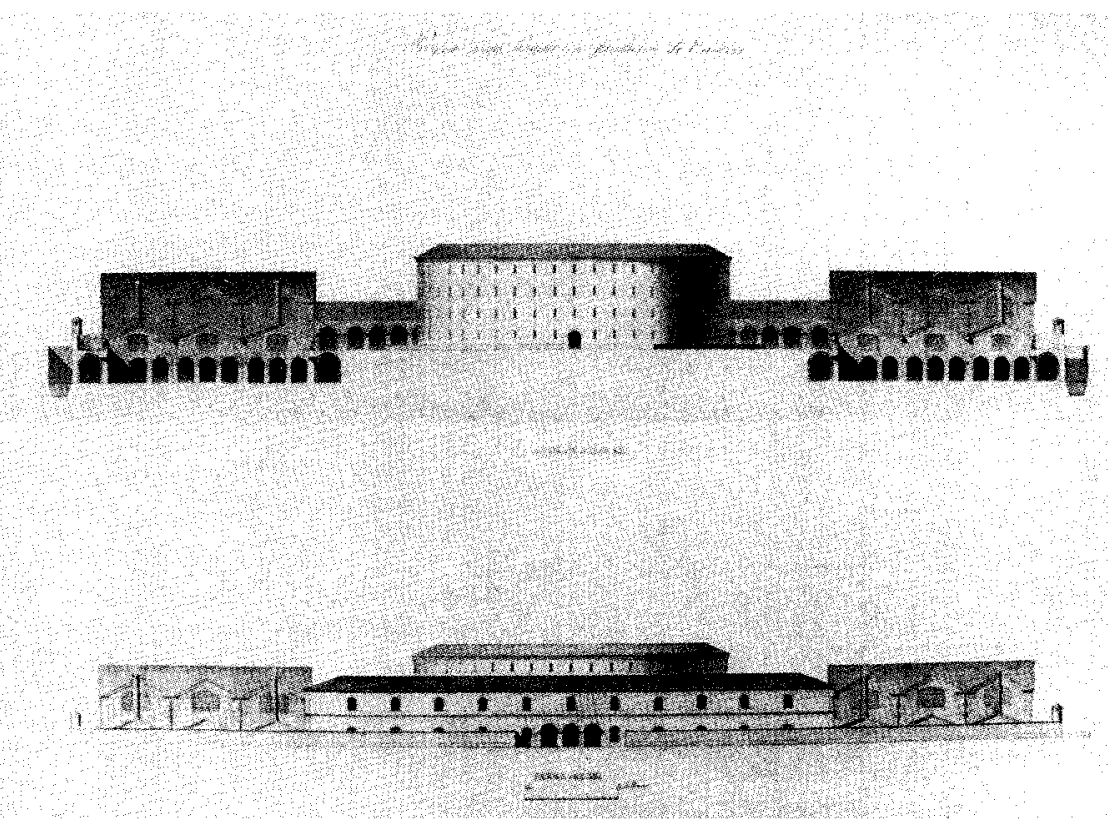

Lám. 12. Fachada del proyecto de Fabio Gago para un presidio con fundición de cañones para Sevilla. 1847. 
una cierta unidad de intenciones, casi siempre expresas en los informes facultativos correspondientes. Resulta imprescindible indicar aquí que la forma al seguir a la función difiere de unos casos a otros, pues hay una gran variedad de subtipos de cárceles según su destino secundario. No podía representarse lo mismo una cárcel para reos de Estado y nobles que una cárcel taller, por ejemplo. De aquí la gran riqueza de representaciones exteriores de este tipo de edificio. La unidad se halla en su terrible primera finalidad misma de ser lugar de retención de presos y de aislamiento del mundo exterior; pero su diferencia reside en la diversidad de finalidades secundarias o en la distinta condición de los reclusos, durante una época especialmente "clasicista», demasiado compartimentada y dividida en clases sociales.

Tal vez sea posible concluir que hay una evolución en el diseño de esta tipología arquitectónica, pues la cárcel poco a poco va adquiriendo su peculiar faz, el rostro que los hombres de nuestros días, de tan finales del siglo $x x$, tenemos. En aquellos años de romanticismo clasicista y funcional - quizá pueda parecer una incongruencia ser un romántico funcional- se pensaba que el exterior de tales edificios debía indicar con toda claridad su tan peculiar destino interno. La cárcel no habría de horrorizar ya; pero sí tenía que persuadir y producir tristeza aún. El espectador ante la visión de su fachada sentiría temor de la justicia humana como consecuencia del delito cometido y también, muchas veces, de la divina, pues la capilla suele asomarse en ocasiones sin ninguna discreción, elevándose, sobre los gruesos muros de muchas de estas cárceles. Dios siempre pesa más que los mismos hombres y también castiga en mayor medida. 